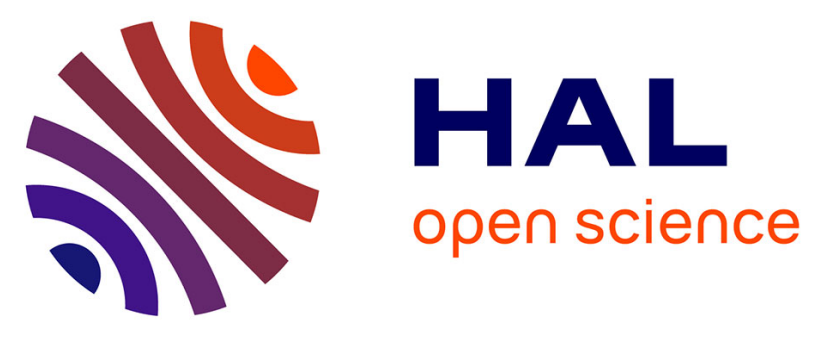

\title{
High-Performance Thermoelectric Bulk Colusite by Process Controlled Structural Disordering
}

Cedric Bourges, Yohan Bouyrie, Andrew R. Supka, Rabih Al Rahal Al Orabi, Pierric Lemoine, Oleg I. Lebedev, Michihiro Ohta, Koichiro Suekuni, Vivian Nassif, Vincent Hardy, et al.

\section{To cite this version:}

Cedric Bourges, Yohan Bouyrie, Andrew R. Supka, Rabih Al Rahal Al Orabi, Pierric Lemoine, et al. High-Performance Thermoelectric Bulk Colusite by Process Controlled Structural Disordering. Journal of the American Chemical Society, 2018, 140 (6), pp.2186-2195. 10.1021/jacs.7b11224 . hal01737387

HAL Id: hal-01737387

https://hal-univ-rennes1.archives-ouvertes.fr/hal-01737387

Submitted on 17 May 2018

HAL is a multi-disciplinary open access archive for the deposit and dissemination of scientific research documents, whether they are published or not. The documents may come from teaching and research institutions in France or abroad, or from public or private research centers.
L'archive ouverte pluridisciplinaire HAL, est destinée au dépôt et à la diffusion de documents scientifiques de niveau recherche, publiés ou non, émanant des établissements d'enseignement et de recherche français ou étrangers, des laboratoires publics ou privés. 


\section{High-performance Thermoelectric Bulk Colusite by Process Controlled Structural Disordering}

Cédric Bourgès, Yohan Bouyrie, ${ }^{\dagger}$ Andrew R. Supka, ${ }^{\dagger}$ Rabih Al Rahal Al Orabi, ${ }^{*}{ }^{*}$ Pierric Lemoine, Oleg I. Lebedev, Michihiro Ohta, Koichiro Suekuni, Vivian Nassif, Vincent Hardy, Ramzy Daou, Yuzuru Miyazaki, Marco Fornari* and Emmanuel Guilmeau*

C. Bourgès, Dr. O.I. Lebedev, Dr. V Hardy, Dr. R. Daou, Dr. E. Guilmeau

Laboratoire CRISMAT, UMR 6508, CNRS, ENSICAEN, 6 Boulevard du Maréchal Juin, 14050 Caen Cedex 04, France

E-mail: emmanuel.guilmeau@ensicaen.fr

Dr. Y. Bouyrie, Dr. M. Ohta

Research Institute for Energy Conservation, National Institute of Advanced Industrial Science and Technology (AIST), Tsukuba, Ibaraki 305-8568, Japan

Dr. P. Lemoine

Institut des Sciences Chimiques de Rennes (ISCR) - UMR CNRS 6226, Rennes, France

Dr. K. Suekuni

Department of Applied Science for Electronics and Materials, Interdisciplinary Graduate School of Engineering Sciences, Kyushu University, Kasuga, Fukuoka 816-8580, Japan

Dr. V. Nassif

Univ. Grenoble Alpes, F-38000 Grenoble, France \& CNRS, Inst. NEEL, F-38042 Grenoble, France

Dr. Y. Miyazaki

Department of Applied Physics, Graduate School of Engineering, Tohoku University, Sendai 980-8579, Japan 


\author{
A. R. Supka, Dr. R. Al Rahal Al Orabi, ${ }^{\#}$ Dr. M. Fornari \\ Department of Physics and Science of Advanced Materials Program, Central Michigan \\ University, Mt. Pleasant, MI 48859, USA \\ E-mail: $\underline{\text { marco.fornari@cmich.edu }}$ \\ E-mail: rabih.orabi@solvay.com
}

\begin{abstract}
High-performance thermoelectric bulk sulfide with the colusite structure is achieved by controlling the densification process and forming short-to-medium range structural defects. A simple and powerful way to adjust carrier concentration combined with enhanced phonon scattering through point defects and disordered regions is described. By combining experiments with band structure and phonons calculations, we elucidate, for the first time, the underlying mechanism at the origin of intrinsically low thermal conductivity in colusite samples as well as the effect of $\mathrm{S}$ vacancies and antisite defects on the carrier concentration. Our approach provides a controlled and scalable method to engineer high power factors and remarkable figures of merit near the unity in complex bulk sulfide such as $\mathrm{Cu}_{26} \mathrm{~V}_{2} \mathrm{Sn}_{6} \mathrm{~S}_{32}$ colusites.

\footnotetext{
\# Present address : Solvay, Design and Development of Functional Materials Department, AXEL'ONE Collaborative Platform - Innovative Materials, 87 Rue des Freres Perret - BP62, 69192 Saint Fons Cedex
} 


\section{Introduction}

The design and optimization of thermoelectric (TE) materials rely on the intricate balance between thermopower $(S)$, electrical resistivity $(\rho)$ and thermal conductivity $(\kappa)$; perfecting such a balance is key to improve energy recovery systems and thermoelectric cooling devices. ${ }^{1}$ A host of materials has been investigated in the past, ${ }^{2-4}$ often neglecting the need to reconcile efficiency with environment and cost constraints both from a composition and/or a processing perspective. For instance, telluride based materials exhibit good performances $^{5-13}$ but are of value only for niche applications due to the escalating prize of tellurium and other less costly compositions require synthesis approaches that are scalable to industrial settings.

Copper sulfides can provide an eco-friendly high-performance low cost alternative since often they contain elements that are abundant in naturally occurring minerals. The values of the figure of merit, $Z T=S^{2} T / \rho \kappa$, observed in $\mathrm{Cu}_{2-x} \mathrm{~S}$, range from 0.5 to 1.7 (at $\mathrm{T}=$ $1000 \mathrm{~K})$ making this material very promising. ${ }^{14-16}$ However, the electro-migration of copper noted in the Cu-S system weakens the stability and their potential for TE applications. ${ }^{14,17}$ In order to mitigate electro-migration, other metallic species besides copper have been added into the composition extending the exploration to complex ternary/quaternary $\mathrm{Cu}$ based sulfides. A non-exhaustive list includes $p$-type tetrahedrite $\mathrm{Cu}_{12-x} \operatorname{Tr}_{x} \mathrm{Sb}_{4} \mathrm{~S}_{13}(Z T \sim 0.80 @ 700$ $\mathrm{K})^{18-31}$ with $\mathrm{Tr}=\mathrm{Mn}, \mathrm{Fe}, \mathrm{Co}, \mathrm{Ni}, \mathrm{Zn}(x \leq 2)$, colusite $\mathrm{Cu}_{26} \mathrm{~V}_{2} \mathrm{Sn}_{6} \mathrm{~S}_{32}(Z T \sim 0.60 @ 700 \mathrm{~K}),{ }^{32,33}$ germanite-derivative $\mathrm{Cu}_{22} \mathrm{Fe}_{8} \mathrm{Ge}_{4} \mathrm{~S}_{32}(Z T \sim 0.17 @ 575 \mathrm{~K}),{ }^{34}$ bornite $\mathrm{Cu}_{5} \mathrm{FeS}_{4}(Z T \sim 0.55 @$ $550 \mathrm{~K}),{ }^{35-37}$ stannoidite $\mathrm{Cu}_{8.5} \mathrm{Fe}_{2.5} \mathrm{Sn}_{2} \mathrm{~S}_{12}(Z T \sim 0.35 @ 630 \mathrm{~K}),{ }^{38} \mathrm{Cu}_{2} \mathrm{SnS}_{3}(Z T \sim 0.56 @ 750$ $\mathrm{K}),{ }^{39} \mathrm{Cu}_{2} \mathrm{ZnSnS}_{4}(Z T \sim 0.35 @ 700 \mathrm{~K})^{40,41}, \mathrm{CuCr}_{2-x} \mathrm{Sb}_{x} \mathrm{~S}_{4}(\mathrm{ZT} \sim 0.45 @ 650 \mathrm{~K})^{42}$ or $n$-type $\mathrm{Cu}_{4} \mathrm{Sn}_{7} \mathrm{~S}_{16}(Z T \sim 0.21 @ 700 \mathrm{~K}),{ }^{43} \mathrm{CuFeS}_{2}(Z T \sim 0.17 @ 630 \mathrm{~K}),{ }^{44,45} \mathrm{Cu}_{2} \mathrm{CoTi}_{3} \mathrm{~S}_{8}(Z T \sim 0.18$ @ $650 \mathrm{~K})^{46}$ and $\mathrm{CuFe}_{2} \mathrm{~S}_{3}(Z T \sim 0.14 @ 700 \mathrm{~K}) .^{47}$ 
Regardless the light atomic masses, most of these materials exhibit low thermal conductivity possibly determined by local structural distortions, rattling phenomena, or strong bond anharmonicity. In $\mathrm{Cu}_{12} \mathrm{Sb}_{4} \mathrm{~S}_{13}$ tetrahedrite, for instance, a low-energy phonon excitation is manifested by the out-of-plane motion of $\mathrm{Cu}$ atoms located in specific crystal site $(12 e)$ which induces scattering effects. It has been pointed out that this anisotropic atomic motion is also favored by the Sb lone pair localized above and below the trigonal plane..$^{19,21,48,49}$ The low thermal conductivity in other $\mathrm{Cu}$ based sulfides was vaguely attributed to the complexity of the crystal structure. ${ }^{32,33,35,39,43}$

Colusite, $\mathrm{Cu}_{26} \mathrm{~V}_{2} \mathrm{Sn}_{6} \mathrm{~S}_{32}$, represents a prototypical complex sulfide (i.e. large unit cell with 66 atoms and light mass elements) with low lattice thermal conductivity, $\kappa_{L}{ }^{32}$ It has been recently studied but the origin of the low thermal conductivity is not understood and the full potential of $\mathrm{Cu}_{26} \mathrm{~V}_{2} \mathrm{Sn}_{6} \mathrm{~S}_{32}$ as an advanced thermoelectric material has not been fully explored. In additional, there are significant discrepancies in the measured properties. Values for the lattice thermal conductivity $\left(\kappa_{L}\right)$ for the pristine phase are ranging from $0.50-0.55 \mathrm{~W} \mathrm{~m}^{-1} \mathrm{~K}^{-}$ ${ }^{1,28,32,50}$ to around $0.90-1.35 \mathrm{~W} \mathrm{~m}^{-1} \mathrm{~K}^{-1}, 33,51$ at $350 \mathrm{~K}$. These two different behaviors seem intimately related to the intrinsic crystallographic structure and the presence of defects. Indeed, by carefully comparing the electrical properties, it can be established that the samples with higher $\kappa_{L}$ values are more metallic with $S$ as low as $30 \mu \mathrm{V} \mathrm{K}^{-1}$ and $\rho$ around $0.6 \mathrm{~m} \Omega \mathrm{cm}$ at 300K. In comparison, samples with low $\kappa_{L}$ values exhibit $S$ of $100-130 \mu \mathrm{V} \mathrm{K}^{-1}$ and $\rho$ in the range $3.5-6.0 \mathrm{~m} \Omega \mathrm{cm}$. This observation indicates interesting sensitivity of the heat and electronic transport to structural features induced by different processing methods (powder synthesis and densification techniques).

We present here a complete study of the bulk properties of colusite including, for the first time, the characterization of the band structure and the vibrational dispersions from first principles calculations. We pinpoint the special role played by $\mathrm{Cu}$ in low frequency optic 
modes and linked such an effect with electronic properties. More importantly, we prove that the TE transport properties of colusite are dramatically influenced by the densification temperature and method, and suggest strategies to control the formation of specific defects. Transport properties and TE efficiency are rationalized within these novel findings in order to provide guidance for the design of TE materials based on tailoring the role of defects.

\section{Results and discussion}

For clarity, this section is arranged by grouping various data by observations and conclusions they generate. First, the band structure and vibrational dispersions from first principles calculations of the pristine $\mathrm{Cu}_{26} \mathrm{~V}_{2} \mathrm{Sn}_{6} \mathrm{~S}_{32}$ are presented. The specific structural features are then explored by means of X-ray/neutron diffraction and transmission electron microscopy. This is followed by the characterization of the electrical and thermal properties whose data are discussed in relation with band structure/vibrational dispersions calculations and structural analysis.

\subsection{Band Structure and phonon dispersions}

Pristine colusite, $\mathrm{Cu}_{26} \mathrm{~V}_{2} \mathrm{Sn}_{6} \mathrm{~S}_{32}$, has a complex cubic structure (space group $P \overline{4} 3 n$, $\mathrm{N}^{\circ}$ 218) ${ }^{52}$ formed by a sulfur corner-sharing tetrahedral network ( $8 e$, and $24 i$ ) centered around $\mathrm{Cu}(6 d, 8 e$, and $12 f)$ and $\mathrm{Sn}(6 c)$. The $\mathrm{V}(2 a)$ atoms occupy a body centered cubic sublattice and are surrounded by $\mathrm{S}$ in $8 e$ (Figure 1). 
Depending on the oxidation states of $\mathrm{V}$ and $\mathrm{Sn}$ (we tentatively assumed $\mathrm{Cu}^{1+}$ and $\mathrm{S}^{2-}$ ), we expect from 4 to 14 holes per unit cell. Indeed, the Fermi level $\left(\mathrm{E}_{\mathrm{F}}\right)$ crosses the valence manifold $0.26 \mathrm{eV}$ below the onset of an energy gap of about $1 \mathrm{eV}$ (Figure 2). The Fermi level lies in the valence manifold indicating a $p$-type metallic behavior, which is in agreement with the experimental transport properties (Figure 8). Integration of the density of states (DOS) from $E_{F}$ to the onset of the energy gap indicates a holes concentration of about $38 \times 10^{20} \mathrm{~cm}^{-3}$ at room temperature which is consistent with $\mathrm{V}^{5+}$ and $\mathrm{Sn}^{4+}$.

The top of the valence band exhibits a multi-valley character with large effective masses 
especially at $\Gamma, \mathrm{X}$, and $\mathrm{M}$ high-symmetry points in the cubic Brillouin zone. As expected, electronic states in the proximity of $\mathrm{E}_{\mathrm{F}}$ originate from the hybridization between the sulfur $p$ orbitals (mainly from $\mathrm{S}$ in $24 i$ ) and substantial contributions from the $\mathrm{Cu} 3 d$-orbitals. The conduction band exhibits an isolated flat manifold below $1.5 \mathrm{eV}$ (energies are measured with respect to $\mathrm{E}_{\mathrm{F}}$ ) mostly associated with $\mathrm{V} d$-orbitals with contribution from the $\mathrm{S}$ atom in $8 e$. The electronic structure seems to indicate that the $\mathrm{V}$ atoms form strong ionic bonds with the surrounding $\mathrm{S}$ (8e, tetrahedral coordination) and, in turn, soften the $\mathrm{S}(8 e)-\mathrm{Cu}(8 e)$ bonds as seen in the $\mathrm{S}-\mathrm{Cu}$ longer distance. This can be justified by the substantial difference in electronegativity between $\mathrm{Cu}$ and $\mathrm{V}$.

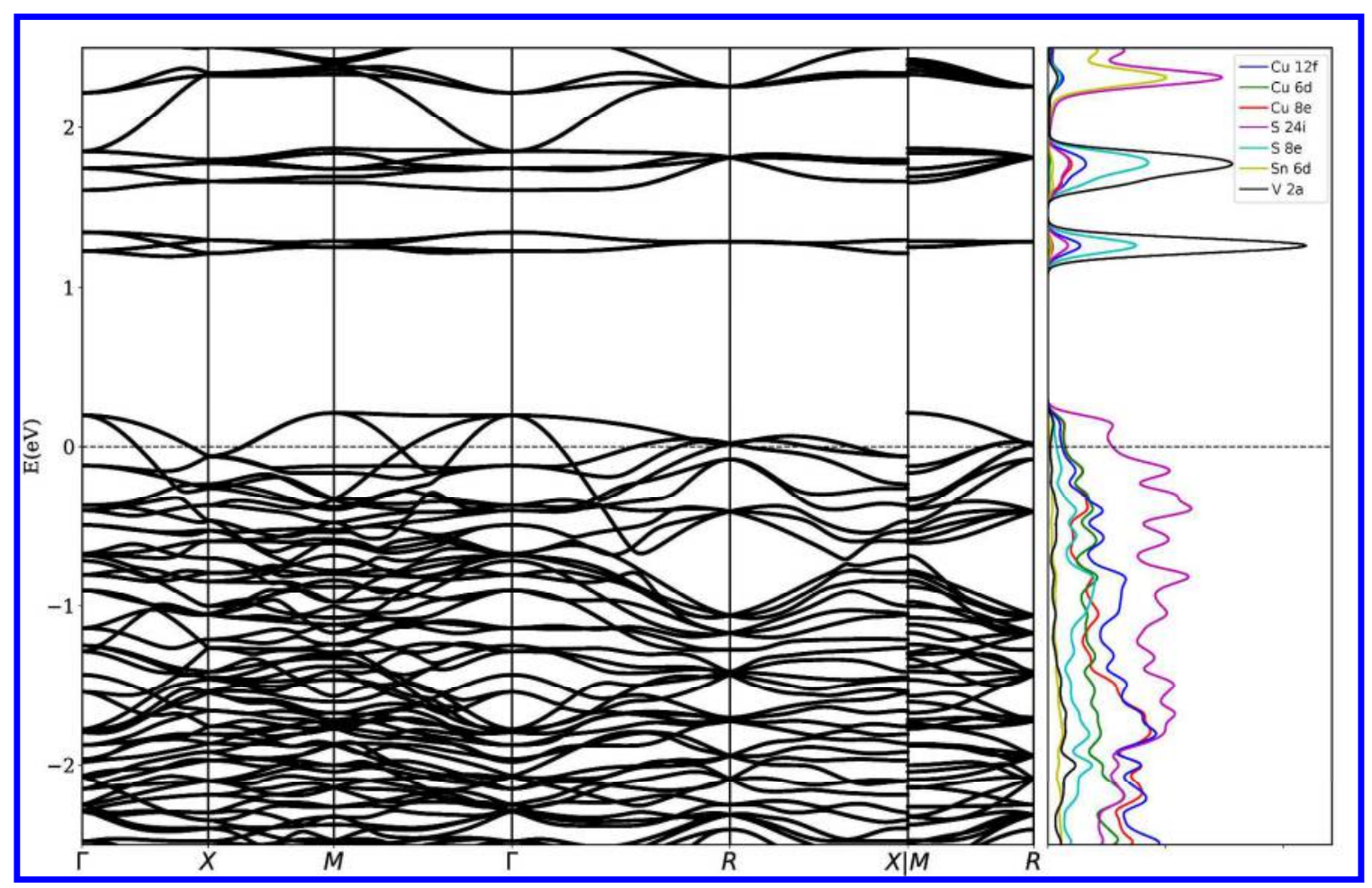

Figure 2. Electronic band structure and atom projected electronic density of states of $\mathrm{Cu}_{26} \mathrm{~V}_{2} \mathrm{Sn}_{6} \mathrm{~S}_{32}$. Hubbard $\mathrm{U}$ corrections were computed self-consistently within the ACBN0 approach (see text): $\mathrm{U}(\mathrm{Cu}$ in $12 f)=7.82, \mathrm{U}(\mathrm{Cu}$ in $8 e)=7.69, \mathrm{U}(\mathrm{Cu}$ in $6 d)=7.78, \mathrm{U}(\mathrm{V})=$ $0.02, \mathrm{U}(\mathrm{Sn})=0.00, \mathrm{U}(\mathrm{S}$ in $24 i)=1.11$ and $\mathrm{U}(\mathrm{S}$ in $8 e)=1.13$. 
As mentioned in the introduction, the origin of the low thermal conductivity of $\mathrm{Cu}_{26} \mathrm{~V}_{2} \mathrm{Sn}_{6} \mathrm{~S}_{32}$ is not understood. We explored the origin of the low thermal conductivity by using density functional theory (DFT) calculations of phonon dispersions and atom-resolved vibrational DOS (VDOS, Figure 3). Although calculations within the harmonic approximation do not provide direct information on the thermal conductivity, the phonon dispersions show compressed acoustic branches which lead to low heat carrier velocity and low thermal conductivity. ${ }^{53,54}$ Also, the presence of low frequencies optic modes (40 and 60 $\mathrm{cm}^{-1}$ ) that can interact with the acoustic vibrations is known to introduce scattering channels that affect the thermal conductivity. ${ }^{55,56}$ This conjecture agrees with the observations in BiOCuS and skutterudites materials that have very low thermal conductivities. ${ }^{55,57-59}$ To better characterize the low frequency modes, we computed the VDOS projected on the atoms, as shown in Figure 3. Surprisingly the largest contribution at low frequency is associated to $\mathrm{Cu}$ in $8 e$ crystallographic site. Due the light mass of $\mathrm{Cu}$, we must assume very soft bonds near $\mathrm{Cu}$ in $8 e$ and assign a major role to its chemical environment on the thermal transport properties as observed in the electronic band structure. This is in agreement with computed total energy response to bond compression for the three $\mathrm{Cu}$ sites that point to softer bonds for the $\mathrm{Cu}$ in $8 e$ (Figure S1). However, more investigations, such as temperature dependent neutron diffraction powder analysis, are needed in order to clarify this point. Quantities derived from our first principles phonon dispersion such as sound velocity and specific heat are also in excellent agreement with the experimental measurements. We computed an average sound velocity of $3150 \mathrm{~m} / \mathrm{s}\left(v_{T}=2350 \mathrm{~m} \mathrm{~s}^{-1}, v_{T}=2613 \mathrm{~m} \mathrm{~s}^{-1}\right.$ and $\left.v_{L}=4485 \mathrm{~m} \mathrm{~s}^{-1}\right)$ and a Debye temperature of $367 \mathrm{~K}$. Experimentally, from specific heat capacity measurements, the Debye temperature was calculated in the range of 350-375 K (Figure S2, Supplementary Information). This corresponds to an average sound velocity of 3017-3230 m $\mathrm{s}^{-1}$. The longitudinal sound velocity was also confirmed by direct measurements $\left(v_{L}=4260 \mathrm{~m}\right.$ 
$\left.\mathrm{s}^{-1}\right)$

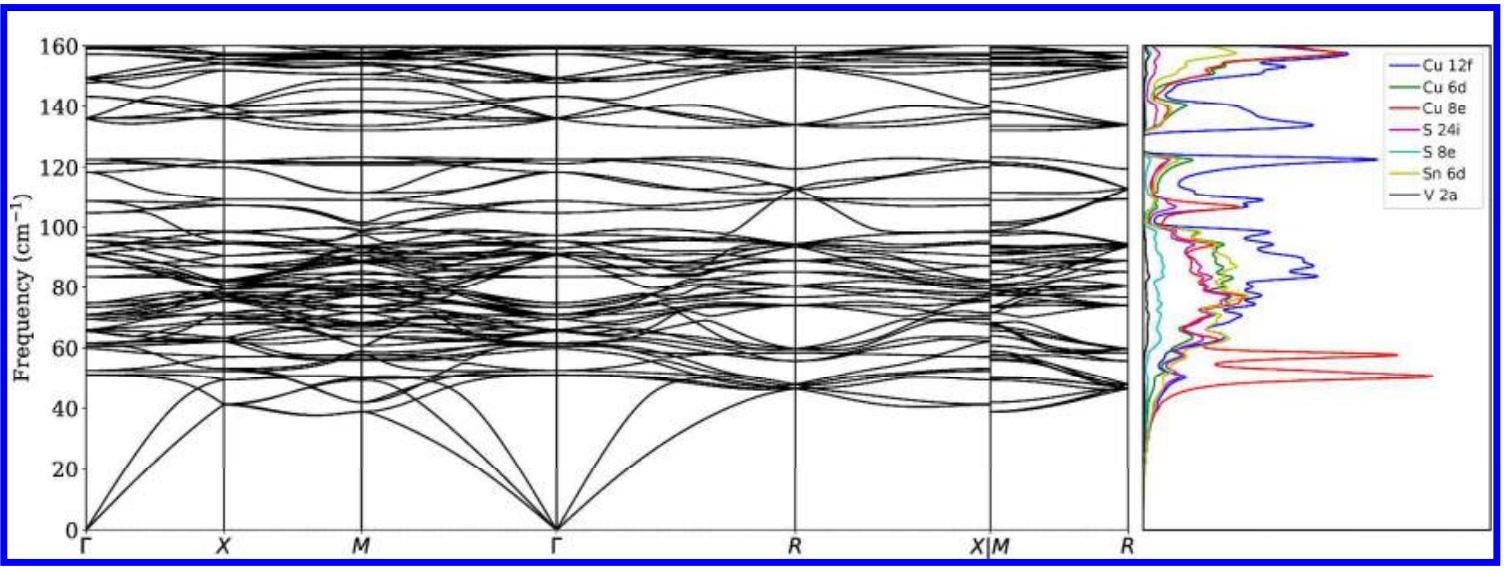

Figure 3. Phonon dispersions and atom-projected vibrational density of states of $\mathrm{Cu}_{26} \mathrm{~V}_{2} \mathrm{Sn}_{6} \mathrm{~S}_{32}$. Optic modes at frequency as low as $40 \mathrm{~cm}^{-1}$ contribute to scattering phenomena that lower the lattice thermal conductivity. Notice the prominent role of $\mathrm{Cu}$ in $8 e$ at low frequency.

\subsection{Synthesis and structural characterization}

Our goal is to understand and optimize the TE properties of colusite using cost effective and scalable methods. We chose to perform reproducible powder synthesis by mechanical-alloying. This technique produces a fine and homogeneous black powder for which the X-ray diffraction data refinements are consistent with the cubic $P \overline{4} 3 n$ space group and cell parameters $(a=10.79(1) \AA)$ expected for colusite. ${ }^{51}$ The obtained powders were then densified using two different consolidation techniques, i.e. spark plasma sintering (SPS) at $873 \mathrm{~K}$ (sample L (Low T)) ${ }^{51}$ and hot pressing (HP) at $1023 \mathrm{~K}$ (sample H (High T)). ${ }^{50}$ The phase purity and crystallinity of the two sintered colusite samples have been confirmed by combined Rietveld refinement of X-ray powder diffraction (XRPD) and neutron powder diffraction (NPD) patterns both recorded at room temperature (Figure $\mathbf{4}$ and S3, respectively). 
Structural parameters determined from these refinements are gathered in Table S1 and Table S2 (bonds distances). The refinements confirm the reported structure but point to some differences on the peak positions and intensities between the two patterns. Indeed, combined Rietveld refinements of the XRPD and NPD patterns lead to slightly larger refined cell parameter for sample H ( $a=10.8289(2) \AA)$ compared to sample L ( $a=10.7701(2) \AA)$. These results suggest the possible existence of structural defects in sample $\mathrm{H}$ and a slight deviation of the expected chemical composition. This conjecture is supported by energy dispersive Xray spectroscopy (EDX) spot analysis performed on twenty grains of each sample. The approximate average compositions (Table S3) are as following: $\mathrm{Cu}_{27.3} \mathrm{~V}_{1.9} \mathrm{Sn}_{6.0} \mathrm{~S}_{31.4}$ for the two samples sintered at $1023 \mathrm{~K}$ (sample $\mathrm{H}$ ) and $\mathrm{Cu}_{25.0} \mathrm{~V}_{1.9} \mathrm{Sn}_{6.0} \mathrm{~S}_{32.6}$ for the two samples sintered at $873 \mathrm{~K}$ (sample L). From these semi-quantitative analyses, we can distinguish a clear tendency towards a copper-rich and sulfur-poor composition for the sample H. Also, larger composition standard deviations are observed in sample $\mathrm{H}$ as compared to sample L. The copper-rich chemical composition combined with larger composition standard deviations and significant larger cell parameter refined for the sample $\mathrm{H}$ suggests a degree of mix random occupation of the $\mathrm{Cu}, \mathrm{Sn}$ and $\mathrm{V}$ sites with possible $\mathrm{S}$ vacancies and atom insertion as interstitials. ${ }^{50}$ Most of these defects influence the carrier concentration and should have effects on the transport properties. It is also implicit that minor traces of $\mathrm{Sn} / \mathrm{V}$ rich phases may exist, even if not detected from XRD/NPD and scanning/transmission electron microscopy analyses. 


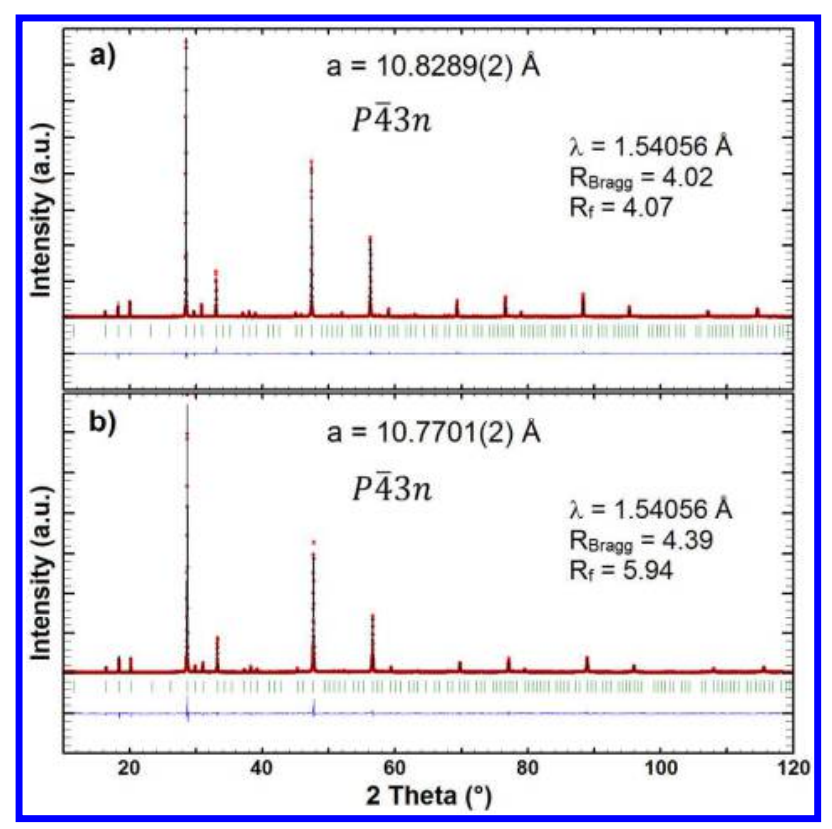

Figure 4. Rietveld refinements of the XRPD patterns recorded at room temperature of the samples H (a) and L (b), sintered respectively at $1023 \mathrm{~K}$ and $873 \mathrm{~K}$.

In order to determine the crystallographic defects in this sample, several structural models were tested to refine the XRPD and NPD data. While attempts to insert metallic atoms in the interstitial $6 b(0,0,1 / 2)$ and/or $24 i(\sim 0, \sim 1 / 4, \sim 1 / 4)$ sites did not improve the initial model, slightly better refinements were obtained considering a partial substitution of $\mathrm{V}$ atoms $(2 a$ site) and/or Sn atoms (6c site) by $\mathrm{Cu}$ atoms. Nevertheless, such metal site random occupancy cannot be determined unambiguously from XRPD and NPD data only but requires complementary local probe investigations such as TEM or resonant contrast diffraction (RCD). To confirm the crystal structure and investigate further the possible formation of structural defects at the atomic level, TEM studies, including electron diffraction (ED) and high angle annular dark field scanning TEM (HAADF-STEM), were undertaken. Several crystallites analyses performed on both samples highlighted that their structure are generally well crystallized in agreement with XRPD and NPD data. The main zones of the $\mathrm{Cu}_{26} \mathrm{~V}_{2} \mathrm{Sn}_{6} \mathrm{~S}_{32}$ ED patterns (Figure 5) and its corresponding HAADF-STEM images show a 
perfectly crystallized structure, which can be indexed based on the cubic $P \overline{4} 3 n(a \sim 10.8 \AA)$ structure, obtained from XRPD and NPD data.

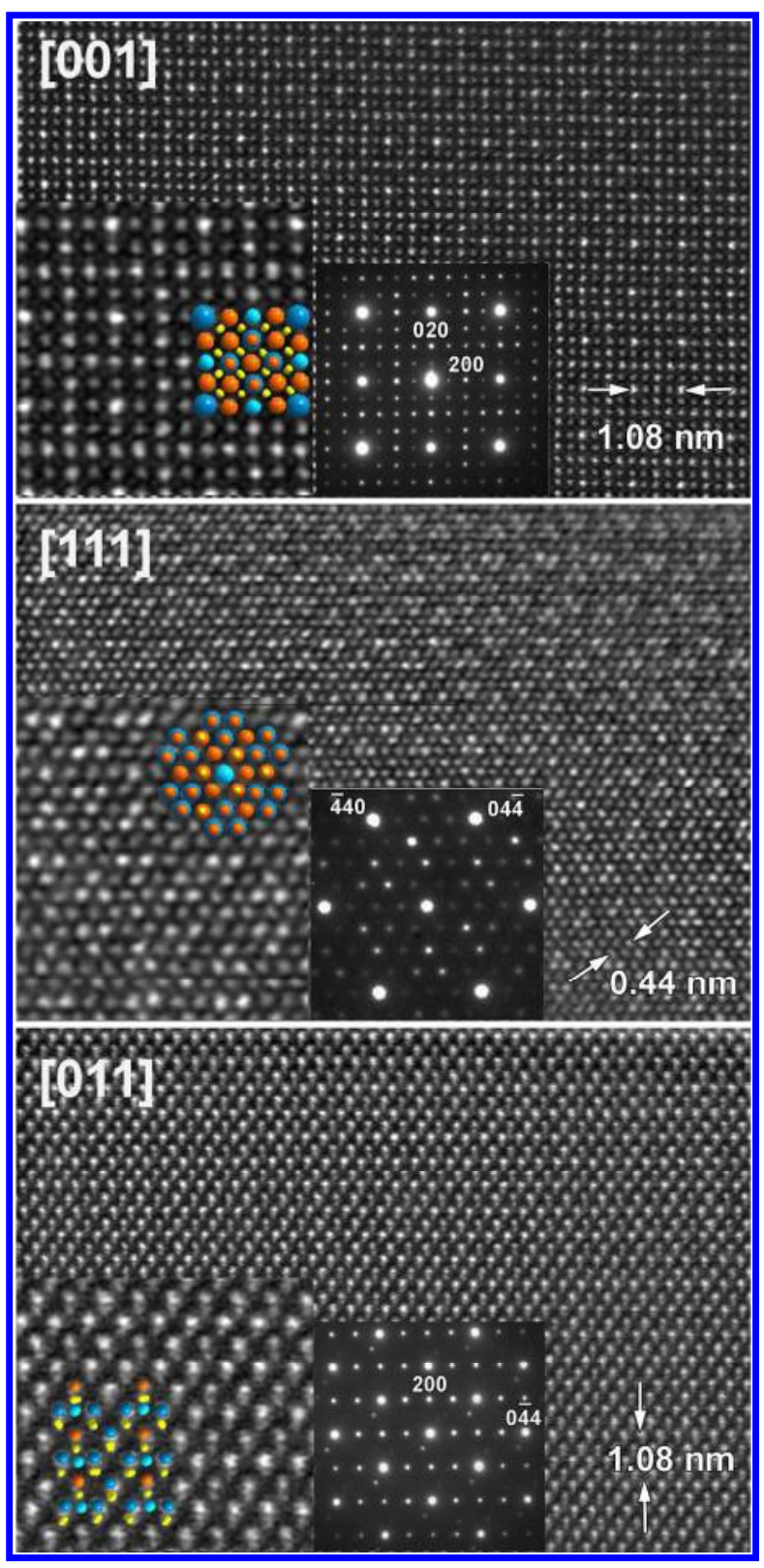

Figure 5. Typical HAADF-STEM images and corresponding ED patterns of both samples L and $\mathrm{H}$ sintered respectively at $873 \mathrm{~K}$ or $1023 \mathrm{~K}$ for main zone axis [001], [111] and [011]. The three figures are representative of both samples L and H. Enlargement images with the overlaid structural models are given as insert. (Sn-blue, V-light blue, Cu-orange, S-yellow) 
No defect regions or superstructures have been found for the sample sintered at $873 \mathrm{~K}$ (sample L). On the contrary, TEM analysis of the sample sintered at $1023 \mathrm{~K}$ (sample $\mathrm{H}$ ) revealed different structural defects/features. The [001] HAADF-STEM image (Figure 6a) clearly shows the presence of $1 \mathrm{D}$ line of point defects. One observes three main sorts of atomic columns intensities. Bearing in mind that contrast in HAADF-STEM image is directly proportional to the thickness and atomic number $\left(\sim Z^{2}\right)$, each column can be attributed to a decaying level of brightness, from pure $\mathrm{Sn}(\mathrm{Z}=50)$ to a mixed $\mathrm{Sn} / \mathrm{V}(23<\mathrm{Z}<50)$ and pure $\mathrm{Cu}(\mathrm{Z}=29)$ (Figures 5 and 6c). In this respect, it is obvious that the $1 \mathrm{D}$ line defects result from the $\mathrm{Sn}$ substitutions with $\mathrm{V}$ and/or $\mathrm{Cu}$ (Figure 6b).

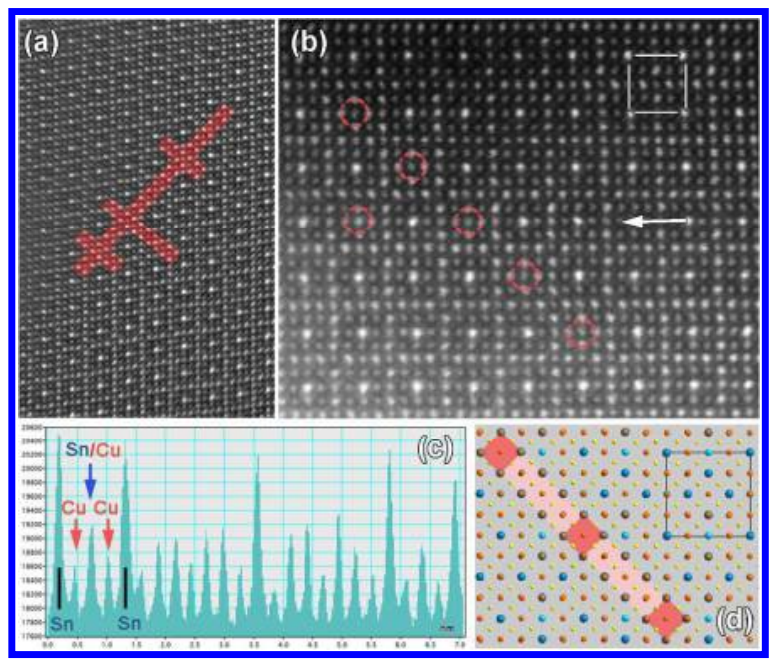

Figure 6. (a) [001] HAADF-STEM image of sample $\mathrm{H}$ sintered at $1023 \mathrm{~K}$. Red color indicates 1D line defects distributed within the perfect crystal of $\mathrm{Cu}_{26} \mathrm{~V}_{2} \mathrm{Sn}_{6} \mathrm{~S}_{32}$. (b) Enlargement part of line defect. Red circle depicted Sn-site defects columns. (c) Intensity line scan profile along the atomic layer indicated by white arrow in (b). There is a clear violation of Sn columns periodicity (higher peaks in the plot profile) corresponding to Sn-site defects. Note that the peak intensity of Sn-site defects columns is similar to those of pure $\mathrm{Cu}$ column suggesting the substitution of $\mathrm{Sn}$ by $\mathrm{Cu}$ atoms. (d) Corresponding structural model of the 1D Sn-vacancy line defect. 
A careful inspection of the images reveals the presence of Sn columns with significantly reduced contrast compared to the regular bright contrast of pure Sn columns (note the intensity profile in Figure 6c). The observed contrast intensity is qualitatively similar to pure $\mathrm{Cu}$ contrast intensity, hence, suggesting the substitution of $\mathrm{Sn}$ with $\mathrm{Cu}$. Due to the lack of spurious Sn-rich phases, however, it is reasonable to assume concurrent random occupation of $\mathrm{V}$ and/or $\mathrm{Cu}$ sites with $\mathrm{Sn}$. It should be also noted that such $\mathrm{Sn}$ substitutions by $\mathrm{Cu}$ and $\mathrm{V}$ were found distributed randomly over the crystal although. Considering the sizes of the tetrahedra (V tetrahedron smaller than $\mathrm{Cu}$ tetrahedron smaller than Sn tetrahedron) and the chemical composition, the $\mathrm{Sn}-\mathrm{Cu}$ antisites are also expected to be kinetically more probable. Also, total energy calculations for the formation energies of antisite defects (Table 1) indicate that the $\mathrm{Cu}-\mathrm{Sn}$ antisites involving $\mathrm{Cu} 6 d$ and $\mathrm{Cu} 8 e$ are favored. The $\mathrm{Cu} 6 d$ and $8 e$ sites form channels around the Sn sites (Figure S4, Supplementary Information) leading to a tendency to form $1 \mathrm{D}$ defects lines. We speculate that ordering along the line (...-Sn-Sn-Cu-Sn-Sn-...) is forced by electrostatic repulsion.

In addition, in some other areas, we observed a clear tendency to form larger 3D disordered regions, as it is shown in Figure 7. These ordered and disordered areas are coherently intergrown with equivalent structural frameworks and unit cell parameters. These results agree with the observations of different domains of ordered and disordered cations in a colusite natural mineral $\mathrm{Cu}_{24.3} \mathrm{~V}_{2.0}\left(\mathrm{As}_{5.7} \mathrm{Sb}_{0.6} \mathrm{Fe}_{0.1}\right) \mathrm{S}_{32}$, as stressed by Spry et al. ${ }^{52}$ They assume that the disordered regions might correspond to a derivated sulvanite-type structure. Finally, from the different structural investigations (XRPD, NPD and HAADF-STEM) and chemical analyses (EDX), we can conclude that the samples sintered at $873 \mathrm{~K}$ are well crystallized and ordered, while increasing the sintering temperature up to $1023 \mathrm{~K}$ favors sulfur volatilization and the creation of short-to-medium range structural defects. Conjunction of S volatilization and high temperature during hot-pressing at $1023 \mathrm{~K}$ probably favor a balance between 
entropy-governed disordered phase and internal energy-governed ordered phase. It verifies the hypothesis proposed by Spry et al., that the disordered domain is the stable form at high temperature. Further experiments will be necessary to establish accurately the crystallization temperature windows and kinetics of formation of such disordered and ordered domains using different densification methods (SPS or HP).

Table 1. Formation energies (in meV) for antisites defects in colusite.

\begin{tabular}{cccccccc}
\hline & $\mathrm{Sn} / \mathrm{V}$ & $\begin{array}{c}\mathrm{Sn} / \mathrm{Cu} \\
12 \mathrm{f}\end{array}$ & $\begin{array}{c}\mathrm{Sn} / \mathrm{Cu} \\
6 \mathrm{~d}\end{array}$ & $\begin{array}{c}\mathrm{Sn} / \mathrm{Cu} \\
8 \mathrm{e}\end{array}$ & $\begin{array}{c}\mathrm{V} / \mathrm{Cu} \\
12 \mathrm{f}\end{array}$ & $\begin{array}{c}\mathrm{V} / \mathrm{Cu} \\
6 \mathrm{~d}\end{array}$ & $\begin{array}{c}\mathrm{V} / \mathrm{Cu} \\
8 \mathrm{e}\end{array}$ \\
\hline $\begin{array}{c}\Delta \mathrm{E} \\
(\mathrm{meV})\end{array}$ & 33 & 42 & 19 & 25 & 21 & 40 & 31 \\
\hline
\end{tabular}

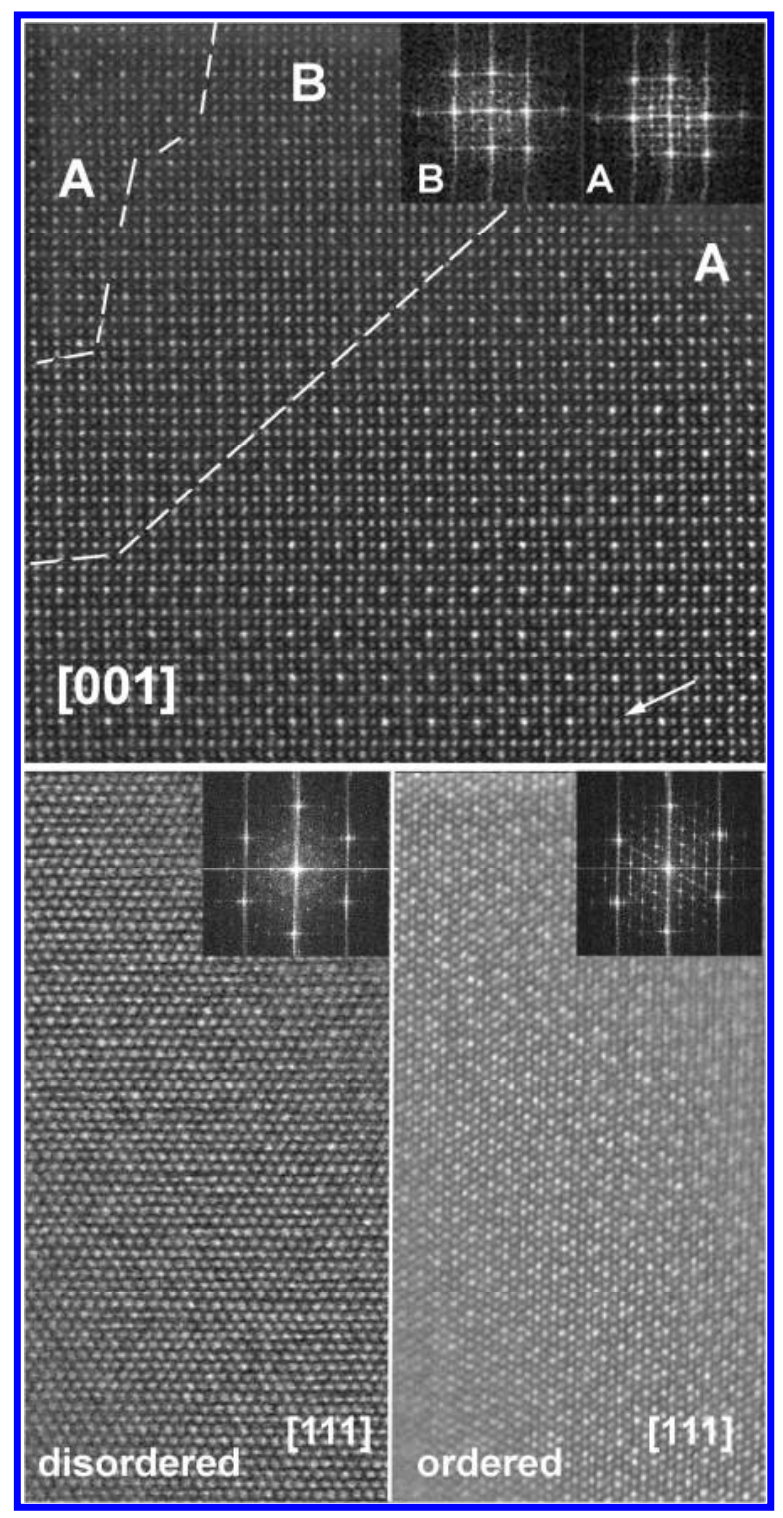


Figure 7. [001] and [111] HAADF-STEM images showing the coexistence of ordered an disordered regions within the same crystallite in the sample $\mathrm{H}$ sintered at $1023 \mathrm{~K}$. Corresponding FT patterns are given as inset. Row indicates a point defect.

\subsection{Electrical and thermal transport properties}

Figure 8a and 8b show, respectively, the electrical resistivity $\rho$ and Seebeck coefficient $S$ of two batches of samples differently sintered over the temperature range $300-675 \mathrm{~K}$. All the properties measurements were performed on four ingots, two sintered at $873 \mathrm{~K}$ and two sintered at $1023 \mathrm{~K}$ (samples L and $\mathrm{H}$, respectively). Both $\rho$ and $S$ increase with temperature and the positive sign of $S$ confirms the $p$-type carrier of colusite, in agreement with the electronic structure calculations. A small dispersion of the electrical properties is observable for both sets of samples, which is consistent with deviation from ideal stoichiometry of colusite. ${ }^{28}$ Overall, samples $\mathrm{H}$ exhibit higher $\rho$ and $S$ compared to the other ones sintered at $873 \mathrm{~K}$. The magnitudes of the electrical properties are in good agreement with previous studies, where two distinct electrical behaviors were observed, i.e. metallic-like ${ }^{33,51}$ and another less conducting behavior. ${ }^{28,32,50}$ In our measurements, $\rho$ and $S$ evolve at room temperature from $0.4-1.0 \mathrm{~m} \Omega \mathrm{cm}$ and $30-45 \mu \mathrm{V} \mathrm{K}^{-1}$ in the samples $\mathrm{L}$, to $1.9-2.8 \mathrm{~m} \Omega \mathrm{cm}$ and to $90-101 \mu \mathrm{V} \mathrm{K}^{-1}$ in the samples $\mathrm{H}$. The significant increase of $\rho$ and $S$ values observed in the latter sample is likely governed by the sulfur deficiency (as mentioned above) due to the volatilization of sulfur during hot pressing at high temperature (1023 K for $1 \mathrm{~h})$.

The carrier concentration of sample L was extracted from Hall measurements. The value of $32.6 \times 10^{20} \mathrm{~cm}^{-3}$ is in good agreement with the computed value of $38 \times 10^{20} \mathrm{~cm}^{-3}$, acknowledging the presence, in a small amount, of $\mathrm{S}$ vacancies (with an estimated concentration of about 0.8 vacancies per unit cell). Defects are affecting the transport 
properties by modifying the charge carrier density and by introducing scattering phenomena that influence the relaxation time (both for charge carriers and heat carriers). We noted earlier that the samples $\mathrm{H}$ sintered at $1023 \mathrm{~K}$ are $\mathrm{S}$ poor and $\mathrm{Cu}$ rich and, additionally, our structural analysis indicates a degree of disorder in the occupation of $\mathrm{Sn}, \mathrm{V}$, and $\mathrm{Cu}$ sites. $\mathrm{S}$ vacancies introduce electrons $\left(\square_{\mathrm{S}}^{2 \bullet}+2 \mathrm{e}^{\prime}+26 \mathrm{Cu}_{\mathrm{Cu}}^{\mathrm{X}}+6 \mathrm{Sn}_{\mathrm{Sn}}{ }^{\mathrm{X}}+31 \mathrm{~S}_{\mathrm{S}}^{\mathrm{X}}+2 \mathrm{~V}_{\mathrm{V}}{ }^{\mathrm{X}}\right)$ whereas V-Sn antisites $\left(\mathrm{V}_{\mathrm{Sn}}{ }^{\bullet}+\mathrm{Sn}_{\mathrm{V}^{\prime}}{ }^{\prime}+26 \mathrm{Cu}_{\mathrm{Cu}}^{\mathrm{X}}+5 \mathrm{Sn}_{\mathrm{Sn}}^{\mathrm{X}}+32 \mathrm{~S}_{\mathrm{S}}^{\mathrm{X}}+\mathrm{V}_{\mathrm{V}}{ }^{\mathrm{X}}\right), \mathrm{Cu}-\mathrm{Sn}$ antisites $\left(\mathrm{Cu}_{\mathrm{Sn}}{ }^{3 \prime}+\mathrm{Sn}_{\mathrm{Cu}}{ }^{3 \bullet}+25\right.$ $\left.\mathrm{Cu}_{\mathrm{Cu}}{ }^{\mathrm{X}}+5 \mathrm{Sn}_{\mathrm{Sn}}{ }^{\mathrm{X}}+32 \mathrm{~S}_{\mathrm{S}}{ }^{\mathrm{X}}+2 \mathrm{~V}_{\mathrm{V}}^{\mathrm{X}}\right)$, and $\mathrm{V}-\mathrm{Cu}$ antisites $\left(\mathrm{Cu}_{\mathrm{V}}{ }^{4}+\mathrm{V}_{\mathrm{Cu}}{ }^{4 \bullet}+25 \mathrm{Cu}_{\mathrm{Cu}}{ }^{\mathrm{X}}+6 \mathrm{Sn}_{\mathrm{Sn}}{ }^{\mathrm{X}}+\right.$ $32 \mathrm{~S}_{\mathrm{S}}^{\mathrm{X}}+1 \mathrm{~V}_{\mathrm{V}}{ }^{\mathrm{X}}$ ) do not seem to modify the carrier concentration. Experimentally, Hall effect characterization indicates, for samples $\mathrm{H}$, a lower carrier concentration of $13.5 \times 10^{20} \mathrm{~cm}^{-3}$ that may be imputed to partial compensation of the intrinsic hole population due to $\mathrm{S}$ vacancies (comparing theoretical data on pristine colusite we estimated that the vacancies density is roughly 1.5 defects per unit cell, the double with respect to samples L). An alternative possibility is that the decrease in the holes concentration is due to the presence of interstitial copper cations $\left(\mathrm{Cu}_{\mathrm{i}}^{\bullet}+\mathrm{e}^{\prime}+26 \mathrm{Cu}_{\mathrm{Cu}}^{\mathrm{X}}+6 \mathrm{Sn}_{\mathrm{Sn}}{ }^{\mathrm{X}}+32 \mathrm{~S}_{\mathrm{S}}{ }^{\mathrm{X}}+2 \mathrm{~V}_{\mathrm{V}}{ }^{\mathrm{X}}\right) \cdot{ }^{50}$ However, this would require larger defect density that was not evidenced from the structural analysis. From a structural point of view, the smaller unit cell and shorter $\mathrm{Cu}-\mathrm{S}$ bond distances observed in sample L (Tables S1 and S2) may be also an indication of its larger $\mathrm{Cu}(\mathrm{II})$ content. However, the correlation between hole concentration and bond distances in the two samples must be taken with caution due the disordered character of sample H. Finally, the Hall mobilities are about $4.3 \mathrm{~cm}^{2} \mathrm{~V}^{-1} \mathrm{~s}^{-1}$ for samples $\mathrm{L}$ and $2.1 \mathrm{~cm}^{2} \mathrm{~V}^{-1} \mathrm{~s}^{-1}$ for samples $\mathrm{H}$ in agreement with the additional scattering effects associated with mass and chemical disorder on the metal sites. (see Figure S5).

In addition to possibly introduce charge carriers in the crystal, defects modify the electronic structure and may influence indirectly the carrier concentration. By performing calculations, we noted that $\mathrm{Sn}-\mathrm{Cu}$ antisites do modify indirectly the charge concentration 
increasing it from $38 \times 10^{20} \mathrm{~cm}^{-3}$ to $46 \times 10^{20} \mathrm{~cm}^{-3}(\mathrm{~T}=300 \mathrm{~K})$. Using this new value for the theoretical carrier concentration, sample $\mathrm{H}$ may have an excess of holes that, in order to reconcile theory and experiments, should be compensated by additional S vacancies (with a total concentration of about 2 vacancy/unit cell if we exclude other compensating mechanisms). To estimate the effect of defects on electronic relaxation time, we have fitted theoretical calculations performed in the constant relaxation time approximation to the experimental measurements of the resistivity and estimated the temperature effect on the relaxation time. Results point to a scattering time of sample H $2.5-3.0$ times larger than the one of sample L. Interestingly enough, the simultaneous increase of carrier concentration due to local rearrangement of the electronic structure and scattering time due to $\mathrm{S}$ vacancy formation modifies significantly the electrical properties.

The power factor $(P F)$ temperature dependences, presented in Figure 8e, shows that both sample batches reach similar values at high temperature with a maximum ranging around 0.70 $-0.75 \mathrm{~mW} \mathrm{~m}^{-1} \mathrm{~K}^{-2}$ at $675 \mathrm{~K}$. These values are in good agreement with previous studies on $\mathrm{Cu}_{26} \mathrm{~V}_{2} \mathrm{Sn}_{6-x} \mathrm{~S}_{32}$ (with $\left.x=0.5\right)^{28}$ or $\mathrm{Cu}_{26} \mathrm{Ta}_{2} \mathrm{Sn}_{6} \mathrm{~S}_{32}$ colusites, ${ }^{50}$ but remain lower than the value of $0.92 \mathrm{~mW} \mathrm{~m}^{-1} \mathrm{~K}^{-2}$ reported at $700 \mathrm{~K}$ for the $\mathrm{Cu}_{25} \mathrm{ZnV}_{2} \mathrm{Sn}_{6} \mathrm{~S}_{32}$ composition. ${ }^{51}$ 


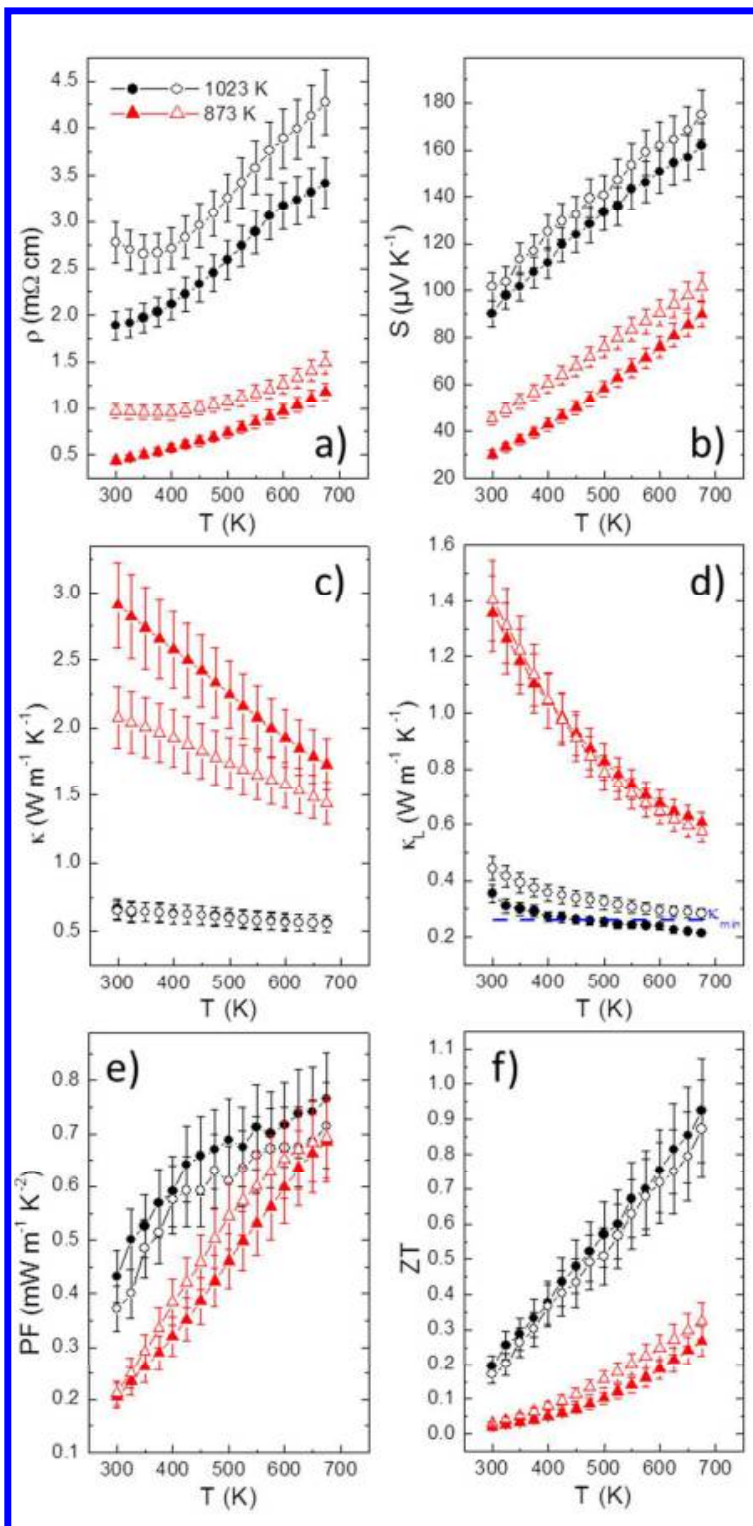

Figure 8. Tempera thermal conductivity $(\kappa)$, d) lattice thermal conductivity $\left(\kappa_{L}\right)$, e) power factor $(P F)$, and f) dimensionless figure of merit $Z T$ of samples $\mathrm{L}$ and $\mathrm{H}$, sintered at $873 \mathrm{~K}$ and $1023 \mathrm{~K}$, respectively.

The temperature dependences of the total $(\kappa)$ and the lattice component $\left(\kappa_{L}\right)$ of the thermal 
conductivity are presented in Figures $\mathbf{8 c}$ and $\mathbf{8 d}$, respectively. All the samples evidence a decrease of $\kappa$ from $300 \mathrm{~K}$ to $675 \mathrm{~K}$. However, two distinct magnitudes for both $\kappa$ and $\kappa_{L}$ are clearly visible depending on the sintering temperature. As previously reported ${ }^{51}$ mechanicalalloyed powders sintered at $873 \mathrm{~K}$ have relatively high $\kappa$ values of $2.1-2.9 \mathrm{~W} \mathrm{~m}^{-1} \mathrm{~K}^{-1}$ at 300 $\mathrm{K}$ and $1.4-1.7 \mathrm{~W} \mathrm{~m}^{-1} \mathrm{~K}^{-1}$ at $675 \mathrm{~K}$. This large magnitude is linked to i) the metallic behavior and the large carrier contribution to the thermal conductivity $\left(\kappa_{e} \sim 0.8-1.5 \mathrm{~W} \mathrm{~m}^{-1} \mathrm{~K}^{-1}\right.$ at 300 $\mathrm{K}$ ) and ii) the absence of structural defects (as seen above). Furthermore, it is obvious that increasing sintering temperature up to $1023 \mathrm{~K}$ induces a remarkable decrease in $\kappa$ with ultralow values of $0.65-0.67 \mathrm{~W} \mathrm{~m}^{-1} \mathrm{~K}^{-1}$ at $300 \mathrm{~K}$ and $0.55-0.56 \mathrm{~W} \mathrm{~m}^{-1} \mathrm{~K}^{-1}$ at $675 \mathrm{~K}$, as reported earlier. $^{28,32,48,50}$ The $\kappa$ reduction can be attributed to i) the decrease of $\kappa_{e}\left(\sim 0.3-0.4 \mathrm{~W} \mathrm{~m}^{-1} \mathrm{~K}^{-1}\right.$ at $300 \mathrm{~K}$ ) and ii) the enhanced phonon scattering induced by the existence of structural defects leading to a more disordered character of the samples sintered at $1023 \mathrm{~K} . \kappa_{L}$ is then reduced on the full temperature range with a significant decrease from $1.3 \mathrm{~W} \mathrm{~m}^{-1} \mathrm{~K}^{-1}$ for the samples sintered at $873 \mathrm{~K}$ to $0.3-0.4 \mathrm{~W} \mathrm{~m}^{-1} \mathrm{~K}^{-1}$ for the samples sintered at $1023 \mathrm{~K}$, which is close to the computed theoretical minimum lattice thermal conductivity $\left(k_{\min }=0.27 \mathrm{~W} \mathrm{~m}^{-1} \mathrm{~K}^{-1}\right) \mathrm{using}$ the shortest scattering distance within the model proposed by Cahill et al. ${ }^{60}$

Based on our structural analyses, the origin of the low lattice thermal conductivity in samples $\mathrm{H}$ is mainly attributed to the scattering effects induced by $\mathrm{S}$ vacancies and cationic disorder, that scatters short-wavelength phonons. In addition, the ordered and disordered regions are coherently intergrown, and their interfaces can also contribute to scattering of phonons with medium wavelengths, meanwhile maintaining good carrier transport without excessive scattering. ${ }^{10,61}$ This statement is also supported by the decrease of the measured sound velocities from $4260 \mathrm{~m} \mathrm{~s}^{-1}$ in sample $\mathrm{L}$ down to $3620 \mathrm{~m} \mathrm{~s}^{-1}$ in sample $\mathrm{H}$. Such a reduction indicates that defects modify the vibrational spectrum in addition to introduce additional 
scattering for the heat carriers. Hence, these structural features are unique in terms of enhancing the thermoelectric performances of colusite.

Finally, the temperature dependence of the dimensionless figure of merit, $Z T$, is given in Figure 8f. All samples exhibit similar temperature dependence with a maximum $Z T$ value of 0.93 at $675 \mathrm{~K}$ for the sample sintered at $1023 \mathrm{~K}$. To the best of our knowledge, this is the highest value reported for Sn-based bulk colusite. Compared to the samples sintered at $873 \mathrm{~K}$, there is an improvement of around $300 \%$ of the figure of merit at $675 \mathrm{~K}$. This huge enhancement takes place in the full temperature range.

\section{Conclusion}

We have performed an in-depth analysis of $\mathrm{Cu}_{26} \mathrm{~V}_{2} \mathrm{Sn}_{6} \mathrm{~S}_{32}$ to illustrate the potential of this complex sulfide for thermoelectric applications. Using scalable mechanical alloying synthesis and different densification methods, we demonstrated how point defects can be used to engineer thermoelectric materials. The measurements are rationalized with the aid of total energy and band structure calculations as well as the calculation of harmonic vibrational properties. Our findings include: (1) the thermoelectric properties of colusite can be tailored with appropriate densification strategies, (2) the measured low thermal conductivity is due to the presence of soft $\mathrm{Cu}$ vibration at low frequency combined with the scattering effects induced by $\mathrm{S}$ vacancies and chemical disorder on the metal ions sublattices, (3) the endotaxial nature of this disordered region does not compromise the power factor, (4) lines of point defects form spontaneously because of the specific energetics of antisite defects.

As a result, the $Z T$ value of bulk colusites rises to near unity at $675 \mathrm{~K}$, making this material one of the best $p$-type TE materials in this temperature region. This approach can be extended to other ternary/quaternary metal/semiconductors with the aim to synthesize other disordered TE materials with enhanced performances. This work thus addresses the interest of 
researchers to broaden the scope of prospective TE materials especially among complex sulfide systems.

\section{Experimental Section}

Mechanically alloyed powders of $\mathrm{Cu}_{26} \mathrm{~V}_{2} \mathrm{Sn}_{6} \mathrm{~S}_{32}$ were prepared by milling $5 \mathrm{~g}$ of copper (Alfa Aesar, $99.5 \%$ ), vanadium (Alfa Aesar, $99.5 \%$ ), sulfur (Alfa Aesar, 99.5\%), and tin (Merck, $99.9 \%$ ) in stoichiometric proportions in a planetary ball mill (Fritsch Pulverisette 7 Premium line). The milling was performed during $12 \mathrm{~h}$ at a speed of 600 rotations per minute under argon atmosphere in a $45 \mathrm{~mL}$ tungsten carbide jar containing 10 balls of $10 \mathrm{~mm}$ diameter. It produces a fine black powder. X-ray powder diffraction data collected on this material are consistent with the $P \overline{4} 3 n$ space group and cell parameters expected for colusite as reported elsewhere. $^{51}$ The obtained powder was then densified using two different consolidation techniques: 1) spark plasma sintering (SPS - FCT HPD 25)) during 45 minutes at $873 \mathrm{~K}$ under a uniaxial pressure of $64 \mathrm{MPa}$ with cooling and heating rates of $50 \mathrm{~K} \mathrm{~min}^{-1}$ with a slight over pressure of $+50 \mathrm{hPa}(\mathrm{Ar})$ and 2) hot pressing (HP FUT-17000, TOKYO VACUUM) at $1023 \mathrm{~K}$ for $1 \mathrm{~h}$ under a uniaxial pressure of $70 \mathrm{MPa}$ in Ar gas flow of $300 \mathrm{ml} \mathrm{min}{ }^{-1}$ with heating and cooling rates of $10 \mathrm{~K} \mathrm{~min}^{-1}$ and $20 \mathrm{~K} \mathrm{~min}^{-1}$, respectively. Two ingots were produced for both densification techniques. The geometrical densities of sample L and H are respectively $90.1 \%$ and $89.5 \%$ of the theoretical values determined from XRPD data.

XRPD measurements were performed using a D8 advance diffractometer with silicium band lynx eyes detector $(\mathrm{Cu} \mathrm{K} \alpha$ radiation with $\mathrm{Ge}$ (111) monochromator). Data were collected with the addition of 6 scans over the angular range $10 \leq 2 \theta /{ }^{\circ} \leq 120$ with a step size of $0.0105^{\circ}$, and a step time of $1.3 \mathrm{sec}$ NPD experiments were carried out at the Institut Laue Langevin (ILL), Grenoble, France. Data were collected at 300K using the high-flux neutron 
two-axis powder diffractometer D1B $(\lambda=1.28 \AA)$ equipped with position sensitive detector of 1280 cells covering a total of $128^{\circ}$.

XRPD and NPD patterns were simultaneously refined by Rietveld analysis using the FullProf and WinPlotr software packages. ${ }^{62,63}$ The shape of the diffraction peaks was modelled using a Thompson-Cox-Hastings pseudo-Voigt profile function. ${ }^{64}$ Zero-point shift and asymmetry parameters were systematically refined, and the background contribution was manually estimated. Lattice parameter, atomic positions, and isotropic displacement parameters (i.e. Debye-Waller factors: $B_{\text {iso }}$ ) were finally refined and gathered in Table S1. Bond distances are presented in Table S2.

Energy dispersive X-ray spectroscopy (EDAX EDX detector) spot analyses were performed on twenty grains of each sample (Table S3).

Transmission electron microscopy (TEM) analyses including electron diffraction (ED) and high angle annular dark field scanning TEM (HAADF-STEM) studies were performed by using a JEM200F cold FEG image and probe aberration microscope operated at $200 \mathrm{kV}$, equipped with CENTURIO EDX detector and Quantum GIF. TEM samples were prepared by crushed powder in agate mortar, suspended in n-butanol and then deposited on a Ni holey carbon grid.

The electrical resistivity $(\rho)$ and Seebeck coefficient $(S)$ were measured simultaneously from ingots, from $300 \mathrm{~K}$ up to $675 \mathrm{~K}$ using ULVAC-ZEM3 device under partial helium pressure. An LFA-457 model was used for measuring the thermal diffusivity under argon flow. The thermal conductivity $(\kappa)$ was determined as the product of the geometrical density, the thermal diffusivity and the theoretical heat capacity using DulongPetit approximation. Zero-field heat-capacity measurements were also carried out from $5 \mathrm{~K}$ to $300 \mathrm{~K}$ in the same device using a relaxation method with a $2 \tau$ fitting procedure (Figure S2).

The Wiedemann-Franz law was used to calculate the lattice thermal conductivity by 
subtracting the electronic contribution to the total thermal conductivity $\left(\kappa_{L}=\kappa-\kappa_{e}\right)$. Here, the Lorenz number $L$ was estimated as function of temperature from the experimental Seebeck coefficients using single parabolic band $\operatorname{model}^{65}(L(T)$ curves are displayed in Figure S6). The estimated measurements uncertainties are $6 \%$ for the Seebeck coefficient, $8 \%$ for the electrical resistivity, $11 \%$ for the thermal conductivity and $16 \%$ for the final figure of merit, $Z T{ }^{66}$ Room temperature Hall effect measurements were carried out using Physical Properties Measurement System (PPMS; Quantum Design) under an applied magnetic field up to 9T.

Band structures and phonon dispersions were computed using AFLOW $\pi{ }^{67,68}$. We used ultrasoft PBE pseudopotentials, well converged basis sets corresponding to an energy cut-off of $60 \mathrm{Ry}$ for the wavefunctions and $600 \mathrm{Ry}$ for the charge density. To integrate over the Brillouin zone we used a $4 \times 4 \times 4$ grid. Hubbard U corrections were computed within the (Agapito-Curtarolo-Buongiorno Nardelli (ACBN0) approach, ${ }^{69,70}$ providing the values in Figure 2. For the ACBN0 we used norm-conserving pseudopotentials ( $E_{\text {cut }}=150 \mathrm{Ry}$ ). Electronic transport and carrier concentrations have been computed using interpolated tightbinding hamiltonians as in Ref. ${ }^{71}$

\section{Supporting Information}

Supporting Information is available from the Wiley Online Library or from the author.

Figure S1. Total energy response to the cationic displacement.

Figure S2. Specific heat capacity as a function of temperature.

Figure S3. Rietveld refinement of the NPD patterns.

Figure S4. Structural channels formed by $\mathrm{Cu} 6 d$ and $8 e$ around the $\mathrm{Sn}$ sites.

Figure S5. Relaxation time fitted to experimental data on the resistivity.

Figure S6: Lorentz number as a function of temperature. 
Table S1. Structural parameters determined from combined XRPD/NPD data Rietveld refinements.

Table S2. Interatomic bond distances $(\AA)$.

Table S3. Atomic compositions determined by EDS.

\section{Author Information \\ ${ }^{\dagger}$ Y.B. and A.R.S. contributed equally to this work.}

\section{Acknowledgements:}

The authors gratefully thank J. Lecourt for technical assistance and N. Barrier for sound velocities measurements. The work at AIST and Kyushu University was supported as part of the International Joint Research Program for Innovative Energy Technology funded by Ministry of Economy, Trade and Industry (METI), Japan. The authors are indebted to the Institut Laue Langevin (Grenoble, France) for the provision of research facilities (DOI: 10.5291/ILL-DATA.5-24-585). M.F., R.A.R.A.O and A.S. acknowledges collaboration with the AFLOW Consortium (http://www.aflow.org) under the sponsorship of DOD-ONR (Grants N000141310635 and N000141512266). 


\section{References}

(1) Bell, L. E. Science 2008, 321, 1457.

(2) Snyder, G. J.; Toberer, E. S. Nat.Mater. 2008, 7 (2), 105.

(3) Koumoto, K.; Mori, T. Thermoelectric Nanomaterials, Springer: New York; 2013.

(4) Tan, G.; Zhao, L. D.; Kanatzidis, M. G. Chem. Rev. 2016, 116, 12123.

(5) Pei, Y.; Shi, X.; LaLonde, A.; Wang, H.; Chen, L.; Snyder, G. J. Nature 2011, 473, 66.

(6) Sootsman, J. R.; Chung, D. Y.; Kanatzidis, M. G. Angew. Chemie - Int. Ed. 2009, 48, 8616.

(7) Hsu, K. F.; Loo, S.; Guo, F.; Chen, W.; Dyck, J. S.; Uher, C.; Hogan, T.; Polychroniadis, E. K.; Kanatzidis, M. G. Science 2004, 303, 818.

(8) Hu, X.; Jood, P.; Ohta, M.; Kunii, M.; Nagase, K.; Nishiate, H.; Kanatzidis, M. G.; Yamamoto, A. Energv Environ. Sci. 2016, 9, 517.

(9) Biswas, K.; He, J.; Blum, I. D.; Wu, C.-I.; Hogan, T. P.; Seidman, D. N.; Dravid, V. P.; Kanatzidis, M. G. Nature 2012, 489, 414.

(10) Biswas, K.; He, J.; Zhang, Q.; Wang, G.; Uher, C.; Dravid, V. P.; Kanatzidis, M. G. Nat.Chem. 2011, 3, 160.

(11) Gelbstein, Y.; Davidow, J.; Girard, S. N.; Chung, D. Y.; Kanatzidis, M. Adv. Energy Mater. 2013, 3, 815.

(12) Al Rahal Al Orabi, R.; Mecholsky, N. A.; Hwang, J.; Kim, W.; Rhyee, J. S.; Wee, D.; Fornari, M. Chem. Mater. 2016, 28, 376.

(13) Al Rahal Al Orabi, R.; Hwang, J.; Lin, C. C.; Gautier, R.; Fontaine, B.; Kim, W.; 
Rhyee, J. S.; Wee, D.; Fornari, M. Chem.Mater. 2017, 29, 612.

(14) Liu, H.; Shi, X.; Xu, F.; Zhang, L.; Zhang, W.; Chen, L.; Li, Q.; Uher, C.; Day, T.; Snyder, G. J. Nat Mater 2012, 11, 422.

(15) Ge, Z.; Zhang, B.; Chen, Y.; Yu, Z.; Liu, Y.; Li, J.-F. Chem. Commun. 2011, 47, 12697.

(16) He, Y.; Day, T.; Zhang, T.; Liu, H.; Shi, X.; Chen, L.; Snyder, G. J. Adv. Mater. 2014, 26, 3974.

(17) Dennler, G.; Chmielowski, R.; Jacob, S.; Capet, F.; Roussel, P.; Zastrow, S.; Nielsch, K.; Opahle, I.; Madsen, G. K. H. Adv. Enerov Mater. 2014, 4, 1301581.

(18) Suekuni, K.; Tsuruta, K.; Ariga, T.; Koyano, M. Appl.Phvs. Express 2012, 5, 51201.

(19) Suekuni, K.; Tsuruta, K.; Kunii, M.; Nishiate, H.; Nishibori, E.; Maki, S.; Ohta, M.; Yamamoto, A.; Koyano, M. J.Appl. Phvs. 2013, 113 (4), 43712.

(20) Lu, X.; Morelli, D. T.; Xia, Y.; Zhou, F.; Ozolins, V.; Chi, H.; Zhou, X.; Uher, C. Adv. Enerov Mater. 2013, 3, 342.

(21) Lara-Curzio, E.; May, A. F.; Delaire, O.; McGuire, M. A.; Lu, X.; Liu, C. Y.; Case, E. D.; Morelli, D. T. J.Appl. Phvs. 2014, 115, 193515.

(22) Chetty, R.; Bali, A.; Naik, M. H.; Rogl, G.; Rogl, P.; Jain, M.; Suwas, S.; Mallik, R. C. Acta Mater. 2015, 100, 266.

(23) Bouyrie, Y.; Candolfi, C.; Ohorodniichuk, V.; Malaman, B.; Dauscher, A.; Tobola, J.; Lenoir, B. L.Mater. Chem.C 2015, 3, 10476.

(24) Bouyrie, Y.; Candolfi, C.; Dauscher, A.; Malaman, B.; Lenoir, B. Chem. Mater. 2015, 
27,8354 .

(25) Barbier, T.; Lemoine, P.; Gascoin, S.; Lebedev, O. I.; Kaltzoglou, A.; Vaqueiro, P.; Powell, A. V.; Smith, R. I.; Guilmeau, E. J. Allovs Compd. 2015, 634, 253.

(26) Barbier, T.; Rollin-Martinet, S.; Lemoine, P.; Gascoin, F.; Kaltzoglou, A.; Vaqueiro, P.; Powell, A. V.; Guilmeau, E. L.Am.Ceram.Soc. 2016, 99, 51.

(27) Chetty, R.; Bali, A.; Mallik, R. C. J.Mater. Chem.C 2015, 3, 12364.

(28) Kim, F. S.; Suekuni, K.; Nishiate, H.; Ohta, M.; Tanaka, H. I.; Takabatake, T. J. Appl. Phys. 2016, 119, 175105.

(29) Suekuni, K.; Takabatake, T. APLMater. 2016, 4, 104503.

(30) Lu, X.; Morelli, D. T. ed. C. Uher, (CRC Press. Taylor Fr. Group, Boca Raton, FL) 2016, 16, 473 .

(31) Barbier, T.; Lemoine, P.; Martinet, S.; Eriksson, M.; Gilmas, M.; Hug, E.; Guélou, G.; Vaqueiro, P.; Powell, A. V; Guilmeau, E. RSCAdv. 2016, 6, 10044.

(32) Suekuni, K.; Kim, F. S.; Nishiate, H.; Ohta, M.; Tanaka, H. I.; Takabatake, T. Appl. Phvs. Lett. 2014, 105, 132107.

(33) Suekuni, K.; Kim, F. S.; Takabatake, T. L_Apnl.Phvs. 2014, 116, 63706.

(34) Pavan Kumar, V.; Paradis-Fortin, L.; Lemoine, P.; Caignaert, V.; Raveau, B.; Malaman, B.; Le Caër, G.; Cordier, S.; Guilmeau, E. Inorg. Chem. 2017, 56, 13376.

(35) Qiu, P.; Zhang, T.; Qiu, Y.; Shi, X.; Chen, L. Enerov Environ.Sci. 2014, 7, 4000.

(36) Guélou, G.; Powell, A. V.; Vaqueiro, P. J.Mater. Chem.C 2015, 3, 10624.

(37) Kumar, V. P.; Barbier, T.; Lemoine, P.; Raveau, B.; Nassif, V.; Guilmeau, E. Dalt. 
Trans. 2017, 46, 2174.

(38) Pavan Kumar, V.; Barbier, T.; Raveau, B.; Daou, R.; Malaman, B.; Le Caër, G.; Lemoine, P.; Guilmeau, E. J. Phys. Chem. C 2017.

(39) Shen, Y.; Li, C.; Huang, R.; Tian, R.; Ye, Y.; Pan, L.; Koumoto, K.; Zhang, R.; Wang, Y. Sci.Rep. 2016, 6, 32501.

(40) Liu, M. L.; Huang, F. Q.; Chen, L. D.; Chen, I. W. Appl. Phvs. Lett. 2009, 94, 202103.

(41) Yang, H.; Jauregui, L. A.; Zhang, G.; Chen, Y. P.; Wu, Y. Nano Lett. 2012, 12, 540.

(42) Khan, A. U.; Al Rahal Al Orabi, R.; Pakdel, A.; Vaney, J.; Fontaine, B.; Gautier, R.; Halet, J.; Mitani, S.; Mori, T. Chem.Mater. 2017, 29, 2988.

(43) Bourgès, C.; Lemoine, P.; Lebedev, O. I.; Daou, R.; Hardy, V.; Malaman, B.; Guilmeau, E. Acta Mater. 2015, 97, 180.

(44) Tsujii, N.; Mori, T. Appl. Phvs. Express 2013, 6, 43001.

(45) Xie, H.; Su, X.; Zheng, G.; Yan, Y.; Liu, W.; Tang, H.; Kanatzidis, M. G.; Uher, C.; Tang, X. J.Phvs. Chem. C 2016, 120, 27895.

(46) Hashikuni, K.; Suekuni, K.; Usui, H.; Ohta, M.; Kuroki, K.; Takabatake, T. Appl. Phys. Lett. 2016, 109, 182110.

(47) Barbier, T.; Berthebaud, D.; Frésard, R.; Lebedev, O. I.; Guilmeau, E.; Eyert, V.; Maignan, A. Inorg Chem. Eront. 2017, 4, 424.

(48) Suekuni, K.; Tanaka, H. I.; Kim, F. S.; Umeo, K.; Takabatake, T. J. Phys. Soc. Japan 2015, $84,103601$.

(49) Lai, W.; Wang, Y.; Morelli, D. T.; Lu, X. Adv. Funct.Mater. 2015, 25 (24), 3648. 
(50) Kikuchi, Y.; Bouyrie, Y.; Ohta, M.; Suekuni, K.; Aihara, M.; Takabatake, T. J. Mater. Chem. A 2016, 4 (39), 15207.

(51) Bourgès, C.; Gilmas, M.; Lemoine, P.; Mordvinova, N.; Lebedev, O. I.; Hug, E.; Nassif, V. M.; Malaman, B.; Daou, R.; Guilmeau, E. L.Mater.Chem.C 2016, 4, 7455.

(52) Spry, P. G.; Merlino, S.; Su Wang; Xiaomao Zhang; Buseck, P. R. Am. Mineral. 1994, 79,750 .

(53) Tan, G.; Hao, S.; Zhao, J.; Wolverton, C.; Kanatzidis, M. G. J. Am. Chem. Soc. 2017, $139,6467$.

(54) Lin, H.; Tan, G.; Shen, J. N.; Hao, S.; Wu, L. M.; Calta, N.; Malliakas, C.; Wang, S.; Uher, C.; Wolverton, C.; Kanatzidis, M. G. Angew. Chemie - Int. Ed. 2016, 55, 1.

(55) Vaqueiro, P.; Al Rahal Al Orabi, R.; Luu, S. D. N.; Guélou, G.; Powell, A. V.; Smith, R. I.; Song, J.-P.; Wee, D.; Fornari, M. Phvs. Chem. Chem. Phvs. 2015, 17, 31735.

(56) Christensen, M.; Abrahamsen, A. B.; Christensen, N. B.; Juranyi, F.; Andersen, N. H.; Lefmann, K.; Andreasson, J.; Bahl, C. R. H.; Iversen, B. B. Nat.Mater. 2008, 7, 811.

(57) Wee, D.; Kozinsky, B.; Fornari, M. J. Phvs. Soc. Japan 2013, 82, 14602.

(58) Volja, D.; Kozinsky, B.; Li, A.; Wee, D.; Marzari, N.; Fornari, M. Phys. Rev. B Condens. Matter Mater. Phvs. 2012, 85, 245211.

(59) Al Rahal Al Orabi, R.; Orisakwe, E.; Wee, D.; Fontaine, B.; Gautier, R.; Halet, J.-F.; Fornari, M. J. Mater. Chem. A 2015, 3, 9945.

(60) Cahill, D. G.; Watson, S. K.; Pohl, R. O. Phvs.Rev. B 1992, 46, 6131.

(61) Banik, A.; Vishal, B.; Perumal, S.; Datta, R.; Biswas, K. Energy Environ. Sci. 2016, 9, 
2011.

(62) Rodríguez-Carvajal, J. Phvs.B Condens. Matter 1993, 192 (1-2), 55.

(63) Roisnel, T.; Rodríguez-Carvajal, J. Mater. Sci. Forum 2001, 378-381, 118.

(64) Thompson, P.; Cox, D. E.; Hastings, J. B. J. Appl. Crvstallogr. 1987, 20 (2), 79.

(65) Kim, H. S.; Gibbs, Z. M.; Tang, Y.; Wang, H.; Snyder, G. J. APL Mater. 2015, 3, 41506.

(66) Alleno, E.; Bérardan, D.; Byl, C.; Candolfi, C.; Daou, R.; Decourt, R.; Guilmeau, E.; Hébert, S.; Hejtmanek, J.; Lenoir, B.; Masschelein, P.; Ohorodnichuk, V.; Pollet, M.; Populoh, S.; Ravot, D.; Rouleau, O.; Soulier, M. Rev.Sci.Instrum. 2015, 86, 11301.

(67) Giannozzi, P.; Baroni, S.; Bonini, N.; Calandra, M.; Car, R.; Cavazzoni, C.; Ceresoli, D.; Chiarotti, G. L.; Cococcioni, M.; Dabo, I.; Corso, A. D.; Fabris, S.; Fratesi, G.; de Gironcoli, S.; Gebauer, R.; Gerstmann, U.; Gougoussis, C.; Kokalj, A.; Lazzeri, M.; Martin-Samos, L.; Marzari, N.; Mauri, F.; Mazzarello, R.; Paolini, S.; Pasquarello, A.; Paulatto, L.; Sbraccia, C.; Scandolo, S.; Sclauzero, G.; Seitsonen, A. P.; Smogunov, A.; Umari, P.; Wentzcovitch, R. M. 2009, 21, 395502.

(68) Supka, A. R.; Lyons, T. E.; Liyanage, L.; D’Amico, P.; Al Rahal Al Orabi, R.; Mahatara, S.; Gopal, P.; Toher, C.; Ceresoli, D.; Calzolari, A.; Curtarolo, S.; Nardelli, M. B.; Fornari, M. Comput.Mater.Sci. 2017, 136, 76.

(69) Agapito, L. A.; Ismail-Beigi, S.; Curtarolo, S.; Fornari, M.; Nardelli, M. B. Phys. Rev. B 2016, 93, 35104.

(70) Agapito, L. A.; Curtarolo, S.; Nardelli, M. B. Phvs. Rev. X 2015, 5, 11006.

(71) D’Amico, P.; Agapito, L.; Catellani, A.; Ruini, A.; Curtarolo, S.; Fornari, M.; Nardelli, 
M. B.; Calzolari, A. Phvs. Rev. B 2016, 94, 165166.

1
2
3
4
5
6
7
8
9 


\section{Table of Content}

Cédric Bourgès, Yohan Bouyrie, Andrew R. Supka, Rabih Al Rahal Al Orabi, Pierric Lemoine, Oleg I. Lebedev, Michihiro Ohta, Koichiro Suekuni, Vivian Nassif, Vincent Hardy, Ramzy Daou, Yuzuru Miyazaki, Marco Fornari and Emmanuel Guilmeau

High-performance Thermoelectric Bulk Colusite by Process Controlled Structural Disordering

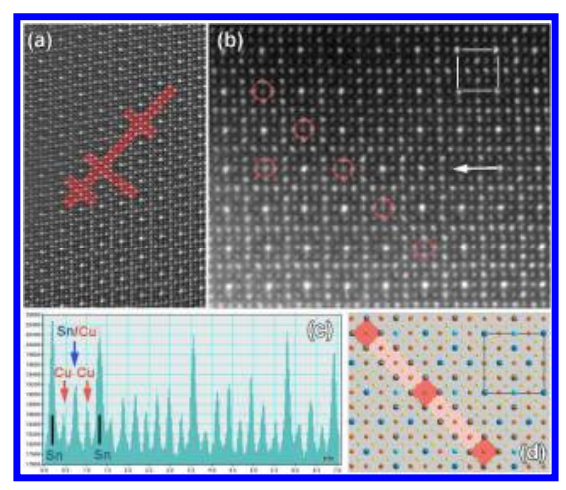


Figure 1. Unit cell of Cu26V2Sn6S32 (space group P4 $3 \mathrm{n}, \mathrm{N}^{\circ} 218$ ). We show the $\mathrm{S}$ in $8 \mathrm{e}$ (yellow) bridging $\mathrm{V}$ (red) with $\mathrm{Cu} 8 \mathrm{e}$ (dark green). $\mathrm{Cu}$ in $6 \mathrm{~d}$ and $12 \mathrm{f}$ are in light green, $\mathrm{Sn}$ in blue, and $\mathrm{S}$ in $24 \mathrm{f}$ are not shown. First principles computed structural parameters are in good agreement with experiments: $a=10.797 \AA$, Cu $(12 f, x=0.748), C u(8 e, x=0.753), C u(6 d), S n(6 c), V(2 a), S(24 i x=0.867, y=0.369, z=0.119)$, and $S(8 e, x=0.620)$.

$373 \times 289 \mathrm{~mm}(299 \times 299$ DPI $)$ 


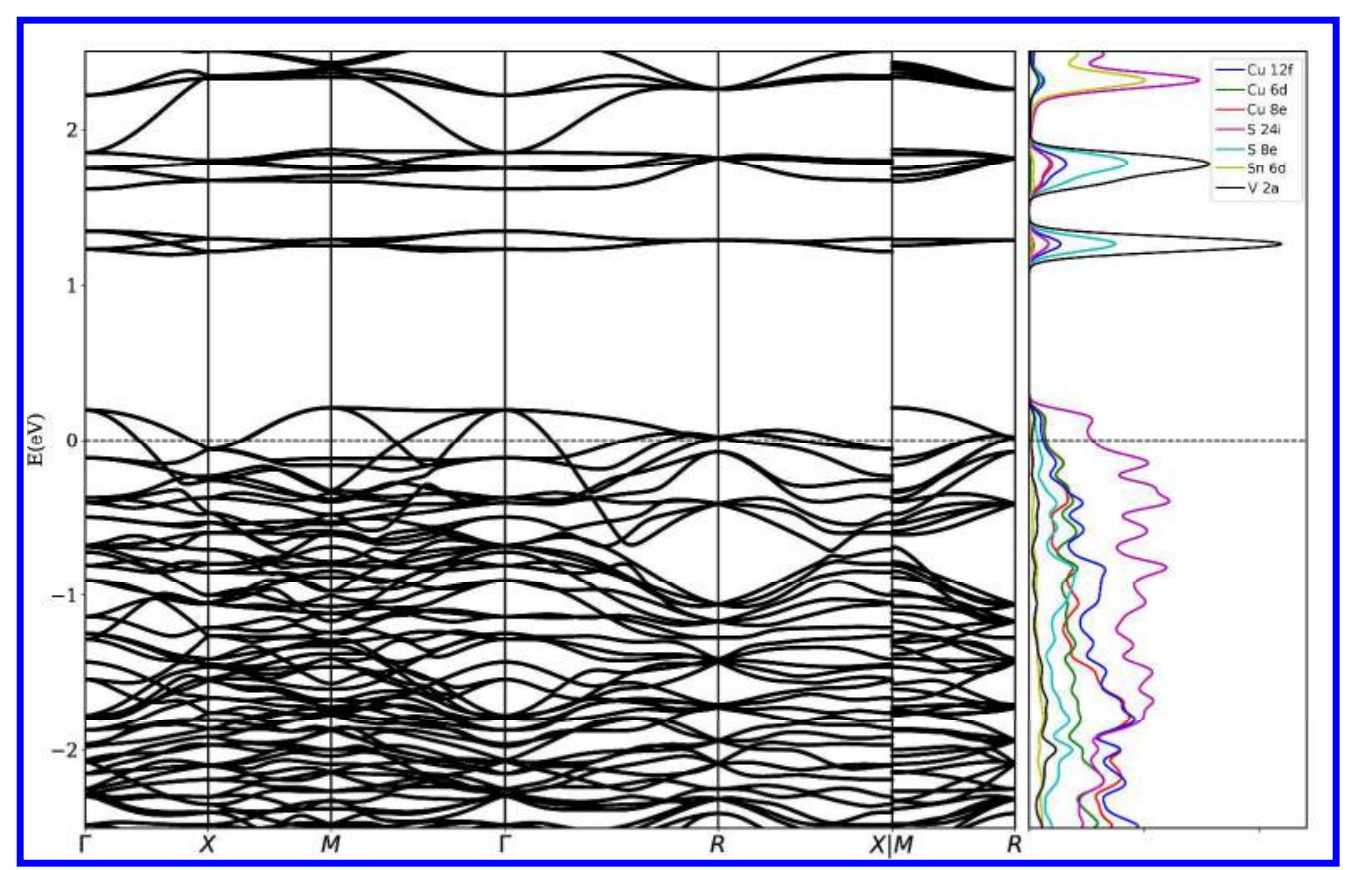

Figure 2. Electronic band structure and atom projected electronic density of states of Cu26V2Sn6S32. Hubbard U corrections were computed self-consistently within the ACBNO approach (see text): $\mathrm{U}(\mathrm{Cu}$ in 12f) $=7.82, \mathrm{U}(\mathrm{Cu}$ in $8 \mathrm{e})=7.69, \mathrm{U}(\mathrm{Cu}$ in $6 \mathrm{~d})=7.78, \mathrm{U}(\mathrm{V})=0.02, \mathrm{U}(\mathrm{Sn})=0.00, \mathrm{U}(\mathrm{S}$ in $24 \mathrm{i})=1.11$ and $\mathrm{U}(\mathrm{S}$ in $8 \mathrm{e})=1.13$.

$476 \times 304 \mathrm{~mm}(300 \times 300 \mathrm{DPI})$ 


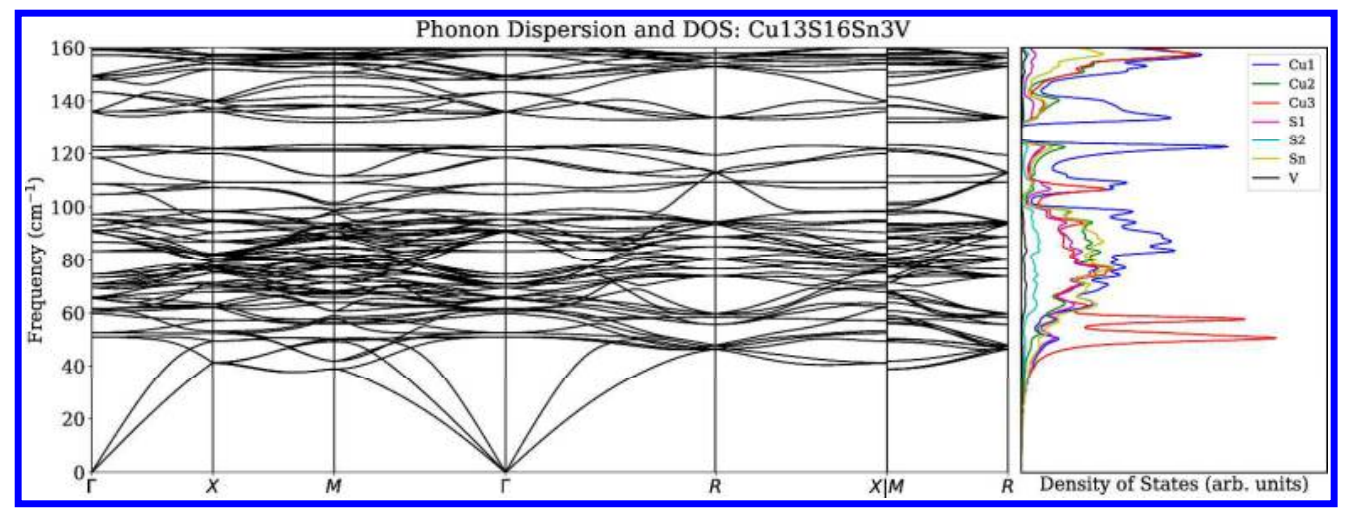

Figure 3. Phonon dispersions and atom-projected vibrational density of states of Cu26V2Sn6S32. Optic modes at frequency as low as $40 \mathrm{~cm}-1$ contribute to scattering phenomena that lower the lattice thermal conductivity. Notice the prominent role of $\mathrm{Cu}$ in $8 \mathrm{e}$ at low frequency.

$498 \times 182 \mathrm{~mm}(300 \times 300 \mathrm{DPI})$ 


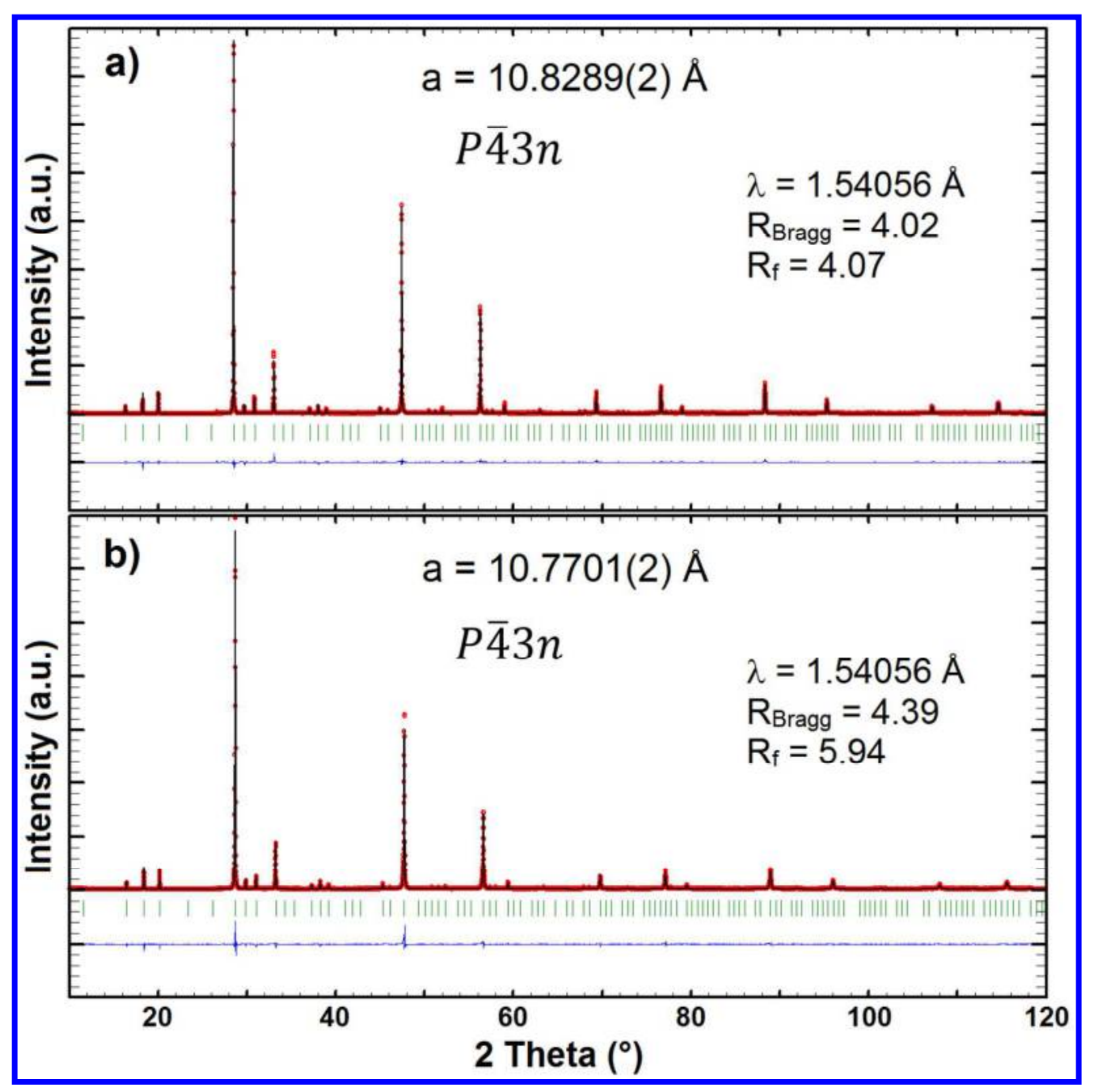

Figure 4. Rietveld refinements of the XRPD patterns recorded at room temperature of the samples $\mathrm{H}(\mathrm{a})$ and $\mathrm{L}$ (b), sintered respectively at $1023 \mathrm{~K}$ and $873 \mathrm{~K}$.

$387 \times 388 \mathrm{~mm}(95 \times 95 \mathrm{DPI})$ 


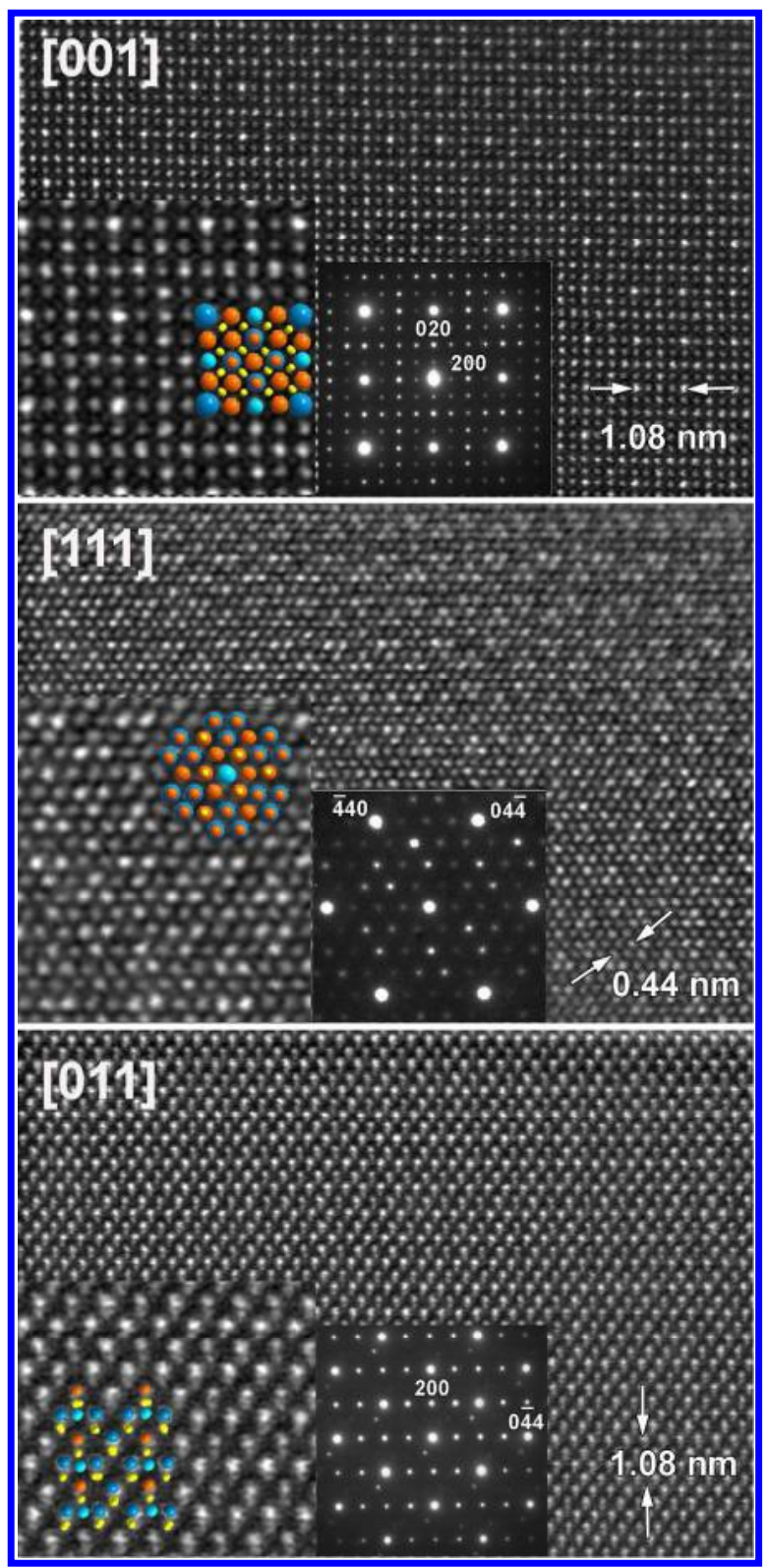

Figure 5. Typical HAADF-STEM images and corresponding ED patterns of both samples $L$ and $H$ sintered respectively at $873 \mathrm{~K}$ or $1023 \mathrm{~K}$ for main zone axis [001], [111] and [011]. Enlargement images with the overlaid structural models are given as insert. (Sn-blue, V-light blue, Cu-orange, S-yellow)

$119 \times 250 \mathrm{~mm}(300 \times 300 \mathrm{DPI})$ 


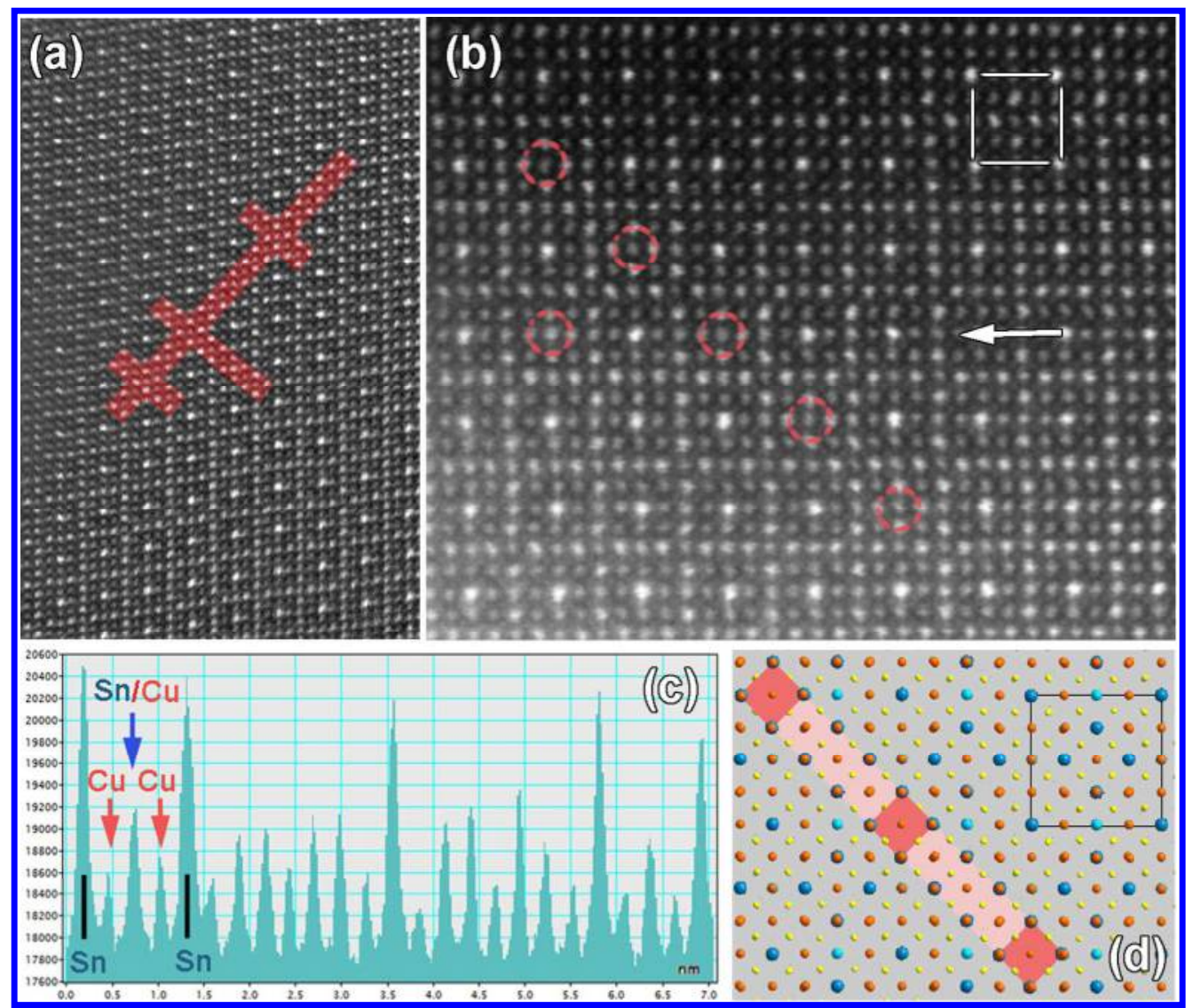

Figure 6. (a) [001] HAADF-STEM image of sample $\mathrm{H}$ sintered at $1023 \mathrm{~K}$. Red color indicates 1D line defects distributed within the perfect crystal of Cu26V2Sn6S32. (b) Enlargement part of line defect. Red circle depicted Sn-site defects columns. (c) Intensity line scan profile along the atomic layer indicated by white arrow in (b). There is a clear violation of Sn columns periodicity (higher peaks in the plot profile) corresponding to Sn-site defects. Note that the peak intensity of Sn-site defects columns is similar to those of pure $\mathrm{Cu}$ column suggesting the substitution of $\mathrm{Sn}$ by $\mathrm{Cu}$ atoms. (d) Corresponding structural model of the 1D Sn-vacancy line defect.

$123 \times 105 \mathrm{~mm}(300 \times 300 \mathrm{DPI})$ 


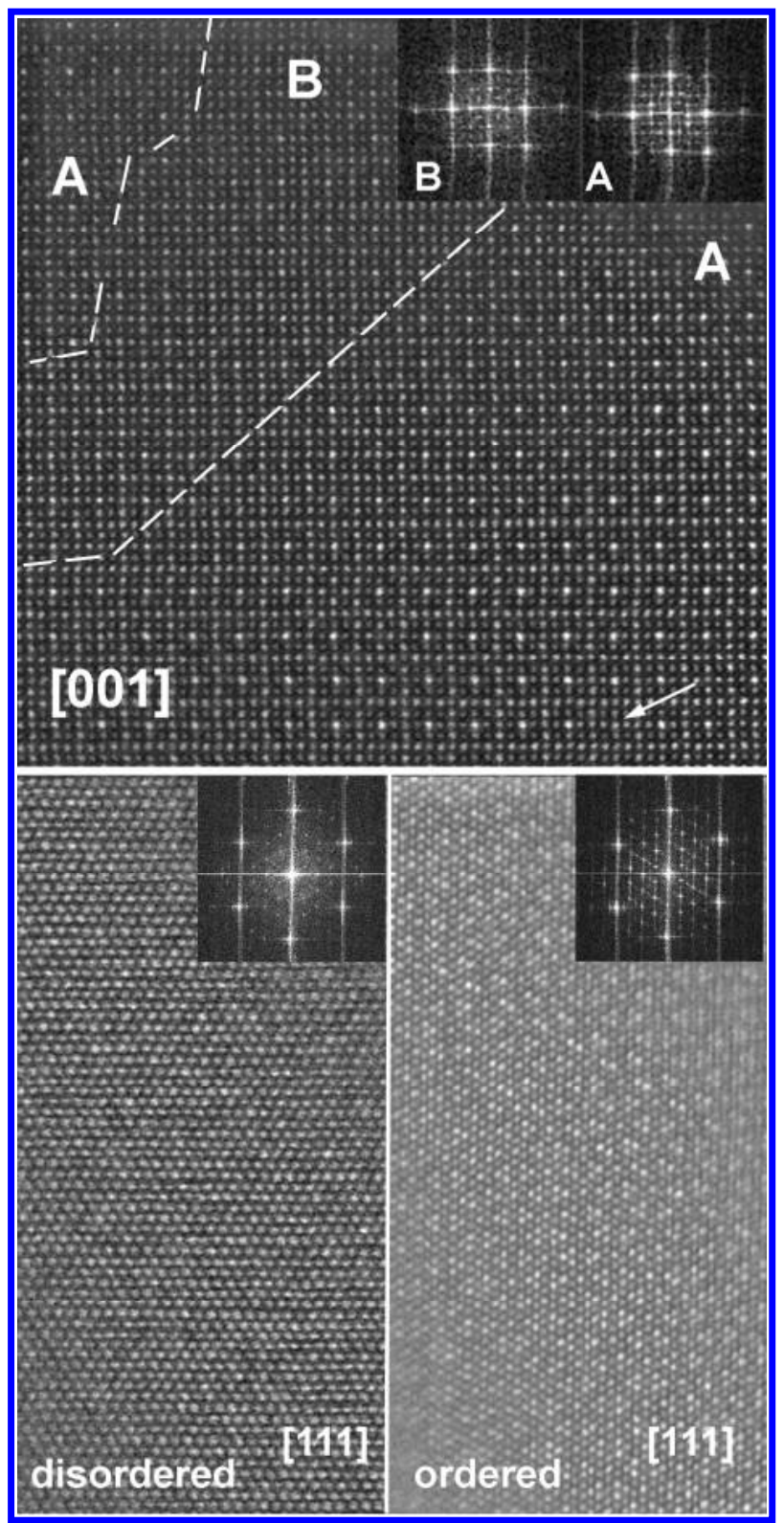

Figure 7. [001] and [111] HAADF-STEM images showing the coexistence of ordered an disordered regions within the same crystallite in the sample $\mathrm{H}$ sintered at $1023 \mathrm{~K}$. Corresponding FT patterns are given as inset. Row indicates a point defect.

$119 \times 238 \mathrm{~mm}(300 \times 300$ DPI $)$ 
Figure 8. Temperature dependence of a) electrical resistivity $(\rho)$, b) Seebeck coefficient (S) c) thermal conductivity $(K), d$ ) lattice thermal conductivity $(K L)$, e) power factor (PF), and f) dimensionless figure of merit ZT of samples L and $\mathrm{H}$, sintered at $873 \mathrm{~K}$ and $1023 \mathrm{~K}$, respectively.

$$
286 \times 523 \mathrm{~mm}(300 \times 300 \text { DPI })
$$

